Chapter 6

\title{
Concepts, Instrumentation and Techniques of Neutron Activation Analysis
}

\author{
Lylia Hamidatou, Hocine Slamene, Tarik Akhal and Boussaad Zouranen \\ Additional information is available at the end of the chapter
}

http://dx.doi.org/10.5772/53686

\section{Introduction}

Analytical science to develop the methodology for the investigation of properties and structure of matter at level of single nucleus, atom and molecule, and scientific analysis to determine either chemical composition or elemental contents in a sample are indispensable in basic research and development, as well as in industrial applications.

Following the discovery of neutron by J. Chadwick in 1932 (Nobel prize, 1935) and the results of F. Joliot and I. Curie in 1934, neutron activation analysis was first developed by G. Hevesy and H. Levi in 1936. They used a neutron source $(226 \mathrm{Ra}+\mathrm{Be})$ and a radiation detector (ionization chamber) and promptly recognized that the element Dy (dysprosium) in the sample became highly radioactive after exposure to the neutron source. They showed that the nuclear reaction may be used to determine the elements present in unknown samples by measuring the induced radioactivity.

Thereafter, the development of the nuclear reactors in the 1940s, the application of radiochemical techniques using low resolution scintillation detectors like NaI (Tl) in the 1950s, the development of semiconductor detectors ( $\mathrm{Ge}, \mathrm{Si}$, etc.) and multichannel analyzer in the 1960s, and the advent of computers and relevant software in the 1970s, the nuclear technique has advanced to become an important analytical tool for determination of many elements at trace level. In spite of the developments in other chemical techniques, the simplicity and selectivity, the speed of operation, the sensitivity and accuracy of NAA have become and maintained its role as a powerful analytical technique. In 2011, Peter Bode describes in his paper "Neutron activation analysis: A primary method of measurements", the history of the development of NAA overall the world [1]. 
Nowadays, there are many elemental analysis methods that use chemical, physical and nuclear characteristics. However, a particular method may be favoured for a specific task, depending on the purpose. Neutron activation analysis (NAA) is very useful as sensitive analytical technique for performing both qualitative and quantitative multielemental analysis of major, minor and traces components in variety of terrestrial samples and extra-terrestrial materials. In addition, because of its accuracy and reliability, NAA is generally recognized as the "referee method" of choice when new procedures are being developed or when other methods yield results that do not agree. It is usually used as an important reference for other analysis methods. Worldwide application of NAA is so widespread it is estimated that approximately 100,000 samples undergo analysis each year.

The method is based on conversion of stable atomic nuclei into radioactive nuclei by irradiation with neutrons and subsequent detection of the radiation emitted by the radioactive nuclei and its identification. The basic essentials required to carry out an analysis of samples by NAA are a source of neutrons, instrumentation suitable for detecting gamma rays, and a detailed knowledge of the reactions that occur when neutrons interact with target nuclei. Brief descriptions of the NAA method, reactor neutron sources, and gammaray detection are given below.

This chapter describes in the first part the basic essentials of the neutron activation analysis such as the principles of the NAA method with reference to neutron induced reactions, neutron capture cross-sections, production and decay of radioactive isotopes, and nuclear decay and the detection of radiation. In the second part we illustrated the equipment requirements neutron sources followed by a brief description of Es-Salam research reactor, gamma-ray detectors, and multi-channel analysers. In addition, the preparation of samples for neutron irradiation, the instrumental neutron activation analysis techniques, calculations, and systematic errors are given below. Some schemes of irradiation facilities, equipment and materials are given as examples in this section.

Finally, a great attention will be directed towards the most recent applications of the INAA and k0-NAA techniques applied in our laboratory. Examples of such samples, within a selected group of disciplines are milk, milk formulae and salt (nutrition), human hair and medicinal seeds (biomedicine), cigarette tobacco (environmental and health related fields) and iron ores (exploration and mining).

All steps of work were performed using NAA facilities while starting with the preparation of samples in the laboratory. The activation of samples depends of neutron fluence rate in irradiation channels of the Algerian Es-Salam research reactor. The radioactivity induced is measured by gamma spectrometers consist of germanium based semiconductor detectors connected to a computer used as a multichannel analyser for spectra evaluation and calculation. Sustainable developments of advanced equipment, facilities and manpower have been implemented to establish a state of the art measurement capability, to implement several applications, etc. 


\section{Neutron activation analysis}

Neutron activation analysis (NAA) is a nuclear process used for determining the concentrations of elements in a vast amount of materials. NAA relies on excitation by neutrons so that the treated sample emits gamma-rays. It allows the precise identification and quantification of the elements, above all of the trace elements in the sample. NAA has applications in chemistry but also in other research fields, such as geology, archaeology, medicine, environmental monitoring and even in the forensic science.

\subsection{Basis principles}

The sequence of events occurring during the most common type of nuclear reaction used for NAA, namely the neutron capture or (n, gamma) reaction, is illustrated in Figure 1. Creation of a compound nucleus forms in an excited state when a neutron interacts with the target nucleus via a non-elastic collision. The excitation energy of the compound nucleus is due to the binding energy of the neutron with the nucleus. The compound nucleus will almost instantaneously de-excite into a more stable configuration through emission of one or more characteristic prompt gamma rays. In many cases, this new configuration yields a radioactive nucleus which also de-excites (or decays) by emission of one or more characteristic delayed gamma rays, but at a much lower rate according to the unique half-life of the radioactive nucleus. Depending upon the particular radioactive species, half-lives can range from fractions of a second to several years.

In principle, therefore, with respect to the time of measurement, NAA falls into two categories: (1) prompt gamma-ray neutron activation analysis (PGNAA), where measurements take place during irradiation, or (2) delayed gamma-ray neutron activation analysis (DGNAA), where the measurements follow radioactive decay. The latter operational mode is more common; thus, when one mentions NAA it is generally assumed that measurement of the delayed gamma rays is intended. About $70 \%$ of the elements have properties suitable for measurement by NAA.

The PGAA technique is generally performed by using a beam of neutrons extracted through a reactor beam port. Fluxes on samples irradiated in beams are in the order of one million times lower than on samples inside a reactor but detectors can be placed very close to the sample compensating for much of the loss in sensitivity due to flux. The PGAA technique is most applicable to elements with extremely high neutron capture cross-sections (B, Cd, Sm, and Gd); elements which decay too rapidly to be measured by DGAA; elements that produce only stable isotopes (e.g. light elements); or elements with weak decay gamma-ray intensities. 2D, 3Danalysis of (main) elements distribution in the samples can be performed by PGAA.

DGNAA (sometimes called conventional NAA) is useful for the vast majority of elements that produce radioactive nuclides. The technique is flexible with respect to time such that the sensitivity for a long-lived radionuclide that suffers from interference by a shorter-lived radionuclide can be improved by waiting for the short-lived radionuclide to decay or quite the contrary, the sensitivity for short-lived isotopes can be improved by reducing the time 


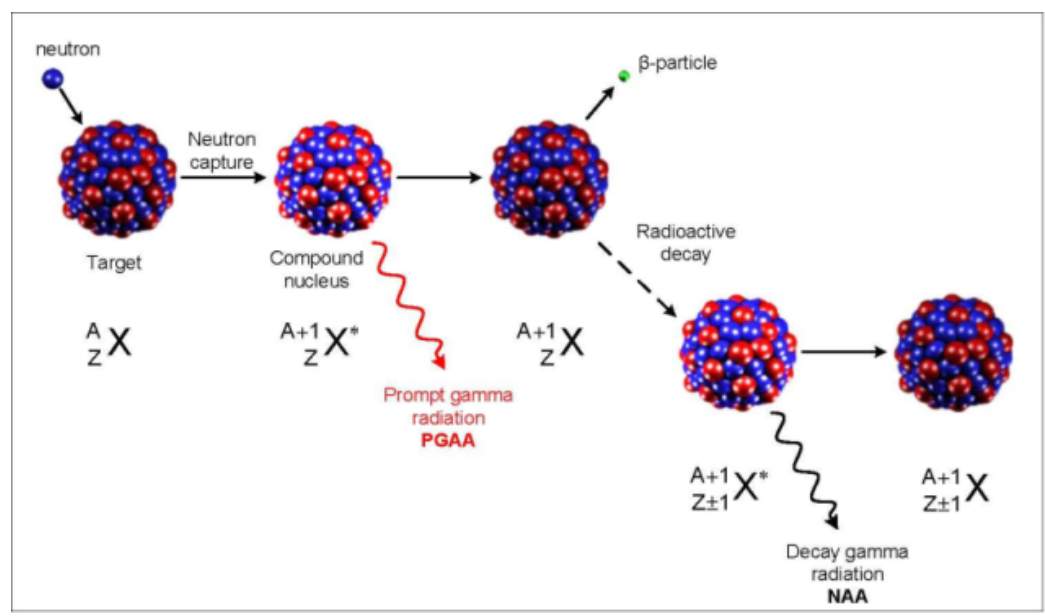

Figure 1. Diagram illustrating the process of neutron capture by a target nucleus followed by the emission of gamma rays.

irradiation to minimize the interference of long-lived isotopes. This selectivity is a key advantage of DGNAA over other analytical methods.

In most cases, the radioactive isotopes decay and emit beta particles accompanied by gamma quanta of characteristic energies, and the radiation can be used both to identify and accurately quantify the elements of the sample. Subsequent to irradiation, the samples can be measured instrumentally by a high resolution semiconductor detector, or for better sensitivity, chemical separations can also be applied to reduce interferences. The qualitative characteristics are: the energy of the emitted gamma quanta $(\mathrm{E} \gamma)$ and the half life of the nuclide $\left(T_{1 / 2}\right)$. The quantitative characteristic is: the I $\gamma$ intensity, which is the number of gamma quanta of energy $\mathrm{E} \gamma$ measured per unit time.

The n-gamma reaction is the fundamental reaction for neutron activation analysis. For example, consider the following reaction:

${ }^{58} \mathrm{Fe}+{ }^{1} \mathrm{n} \rightarrow{ }^{59} \mathrm{Fe}+$ Beta $^{-}+$gamma rays

${ }^{58} \mathrm{Fe}$ is a stable isotope of iron while ${ }^{59} \mathrm{Fe}$ is a radioactive isotope. The gamma rays emitted during the decay of the ${ }^{59} \mathrm{Fe}$ nucleus have energies of 142.4, 1099.2, and $1291.6 \mathrm{KeV}$, and these gamma ray energies are characteristic for this nuclide (see figure 2) [2]. The probability of a neutron interacting with a nucleus is a function of the neutron energy. This probability is referred to as the capture cross-section, and each nuclide has its own neutron energy-capture cross-section relationship. For many nuclides, the capture cross-section is greatest for low energy neutrons (referred to as thermal neutrons). Some nuclides have greater capture cross-sections for higher energy neutrons (epithermal neutrons). For routine neutron activation analysis we are generally looking at nuclides that are activated by thermal neutrons.

The most common reaction occurring in NAA is the $(\mathrm{n}, \gamma)$ reaction, but also reactions such as $(\mathrm{n}, \mathrm{p}),(\mathrm{n}, \alpha),\left(\mathrm{n}, \mathrm{n}^{\prime}\right)$ and $(\mathrm{n}, 2 \mathrm{n})$ are important. The neutron cross section, $\sigma$, is a measure for the 


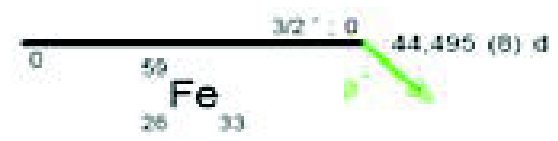

y. Emissicn probabilities per 100 disintegrations

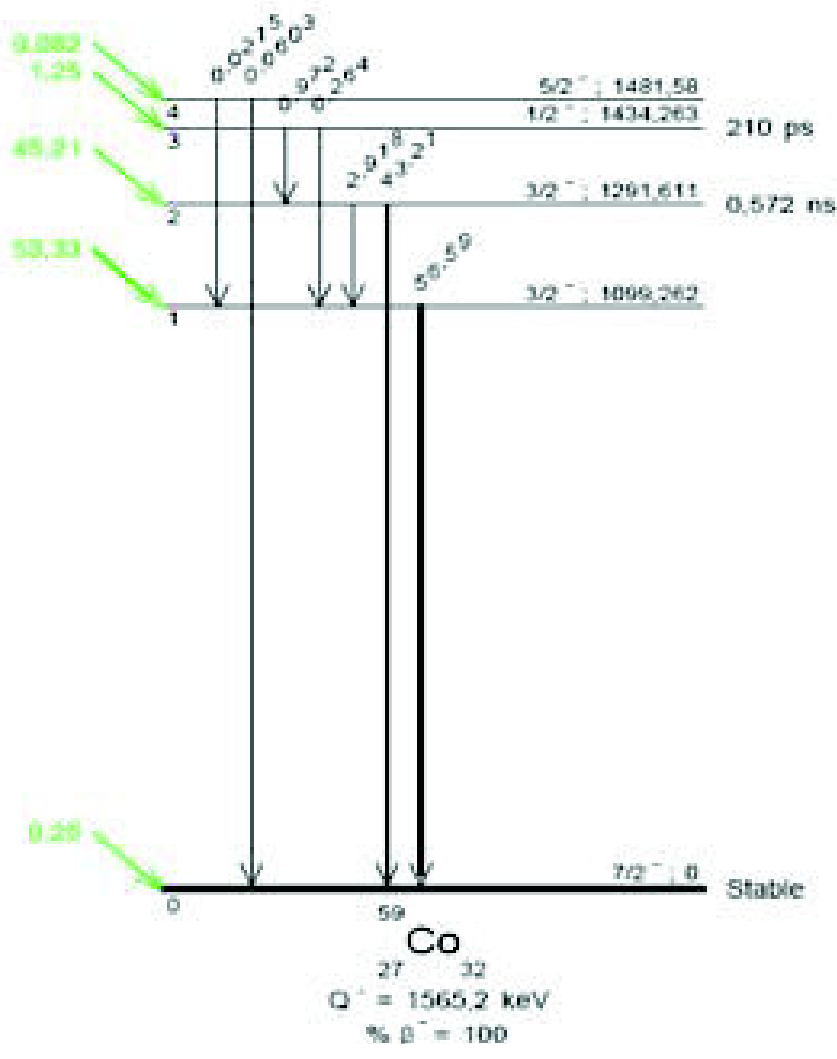

Figure 2. Decay scheme of ${ }^{59} \mathrm{Fe}$.

probability that a reaction will take place, and can be strongly different for different reaction types, elements and energy distributions of the bombarding neutrons. Some nuclei, like 235U are fissionable by neutron capture and the reaction is denoted as $(\mathrm{n}, \mathrm{f})$, yielding fission products and fast (highly energetic) neutrons [1].

Neutrons are produced via

- Isotopic neutron sources, like ${ }^{226} \mathrm{Ra}(\mathrm{Be}),{ }^{124} \mathrm{Sb}(\mathrm{Be}),{ }^{241} \mathrm{Am}(\mathrm{Be}),{ }^{252} \mathrm{Cf}$. The neutrons have different energy distributions with a maximum in the order of 3-4 MeV; the total output is typically $10^{5}-10^{7} \mathrm{~s}^{-1} \mathrm{GBq}^{-1}$ or, for ${ }^{252} \mathrm{Cf}, 2.210^{12} \mathrm{~s}^{-1} \mathrm{~g}^{-1}$. 
- Particle accelerators or neutron generators. The most common types are based on the acceleration of deuterium ions towards a target containing either deuterium or tritium, resulting in the reactions $2 \mathrm{H}(2 \mathrm{H}, \mathrm{n}) 3 \mathrm{He}$ and $3 \mathrm{H}(2 \mathrm{H}, \mathrm{n}) 4 \mathrm{He}$, respectively. The first reaction, often denoted as (D,D), yields monoenergetic neutrons of $2.5 \mathrm{MeV}$ and typical outputs in the order of $10^{8}-10^{10} \mathrm{~s}^{-1}$; the second reaction $(\mathrm{D}, \mathrm{T})$ results in monoenergetic neutrons of 14.7 $\mathrm{MeV}$ and outputs of $10^{9}-10^{11} \mathrm{~s}^{-1}$.

- Nuclear research reactors. The neutron energy distribution depends on design of the reactor and its irradiation facilities. An example of an energy distribution in a light water moderated reactor is given in Fig. 2.3 from which it can be seen that the major part of the neutrons has a much lower energy distribution that in isotopic sources and neutron generators. The neutron output of research reactors is often quoted as neutron fluence rate in an irradiation facility and varies, depending on reactor design and reactor power, between $10^{15}$ and $10^{18} \mathrm{~m}^{-2} \mathrm{~s}^{-1}$.

Owing to the high neutron flux, experimental nuclear reactors operating in the maximum thermal power region of $100 \mathrm{~kW}-10 \mathrm{MW}$ with a maximum thermal neutron flux of $10^{12}-10^{14}$ neutrons $\mathrm{cm}^{-2} \mathrm{~s}^{-1}$ are the most efficient neutron sources for high sensitivity activation analysis induced by epithermal and thermal neutrons. The reason for the high sensitivity is that the cross section of neutron activation is high in the thermal region for the majority of the elements. There is a wide distribution of neutron energy in a reactor and, therefore, interfering reactions must be considered. In order to take these reactions into account, the neutron spectrum in the channels of irradiation should be known exactly. E.g. if thermal neutron irradiations are required, the most thermalized channels should be chosen.

Although there are several types of neutron sources (reactors, accelerators, and radioisotopic neutron emitters) one can use for NAA, nuclear reactors with their high fluxes of neutrons from uranium fission offer the highest available sensitivities for most elements. Different types of reactors and different positions within a reactor can vary considerably with regard to their neutron energy distributions and fluxes due to the materials used to moderate (or reduce the energies of) the primary fission neutrons. This is further elaborated in the title "Derivation of the measurement equation". In our case, the NAA method is based on the use of neutron flux in several irradiation channels of Es-Salam Research reactor. In 2011, Hamidatou L et Al., reported "Experimental and MCNP calculations of neutron flux parameters in irradiation channel at Es-Salam reactor" the core modelling to calculate neutron spectra using experimental and MCNP approaches. The Es-Salam reactor was designed for a thermal power output of $15 \mathrm{Mw}$, with 72 cylindrical cluster fuel elements; each fuel element consists of 12 cylindrical rods of low enriched UO2. In addition the both of fuel throttle tube of the cluster and fuel element tube encloses heavy water as moderator and coolant. The fuel elements are arranged on a heavy water square lattice. The core of the reactor is constituted by a grid containing 72 fuel elements, 12 rods for reactivity control and two experimental channels.

There is also a heavy water in the middle of the core including five experimental channels called inner reflector, In addition, all fuel elements have a reflector at each end called upper 
and lower reflector. The core is reflected laterally by heavy water maintained in aluminium tank followed by the graphite.

\subsection{Neutron activation analysis procedure}

In the majority of INAA procedures thermal reactor neutrons are used for the activation: neutrons in thermal equilibrium with their environment. Sometimes activation with epithermal reactor neutrons (neutrons in the process of slowing down after their formation from fission of $235 \mathrm{U}$ ) is preferred to enhance the activation of elements with a high ratio of resonance neutron cross section over thermal neutron cross section relatively to the activation of elements with a lower such a ratio. In principle materials can be activated in any physical state, viz. solid, liquid or gaseous. There is no fundamental necessity to convert solid material into a solution prior to activation; INAA is essentially considered to be a non-destructive method although under certain conditions some material damage may occur due to thermal heating, radiolysis and radiation tracks by e.g. fission fragments and $\alpha$-radiation emitting nuclei. It is essential to have more than two or three qualified full-time member of the staff with responsibility for the NAA facilities. They should be able to control the counting equipment and have good knowledge of basic principles of the technique. In addition, the facility users and the operators must establish a good channel of communication. Other support staff will be required to maintain and improve the equipment and facility. It seems, therefore, a multi-disciplinary team could run the NAA system well.

The analytical procedure is based on four steps:

Step 1: sample preparation (Figure 3) means in most cases only heating or freeze drying, crushing or pulverization, fractionating or pelletizing, evaporation or pre-concentration, put through a sieve, homogenising, weighing, washing, check of impurities (blank test), encapsulation and sealing irradiation vial, as well as the selection of the best analytical process and the preparation of the standards. The laboratory ambiance is also important for preservation and storage of the samples. Standardization is the basis for good accuracy of analytical tools and often depends on particular technology, facility and personnel. For production of accurate data, careful attention to all possible errors in preparing single or multi-element standards is important, and standards must be well chosen depending on the nature of the samples.

Step 2: irradiation of samples can be taken from the various types of neutron sources according to need and availability. For the INAA, one pneumatic transfer system installed in the horizontal channel at Es-Salam research reactor for short irradiation of samples (Figure 4). In addition, two vertical channels located in different sites of the heavy water moderator and the graphite reflector have been used for long irradiations. The neutron spectrum parameters at different irradiation channels such as alpha, $\mathrm{f}$, Tn, etc are experimentally determined using cadmium ratio, cadmium cover, bare triple monitor and bi-isotopic methods using HФgdhal convention and Westcott formalism Table 1 and Table 2. The calibration of the irradiation positions has been carried out to implement the $\mathrm{k}_{0}$-NAA in our laboratory. 

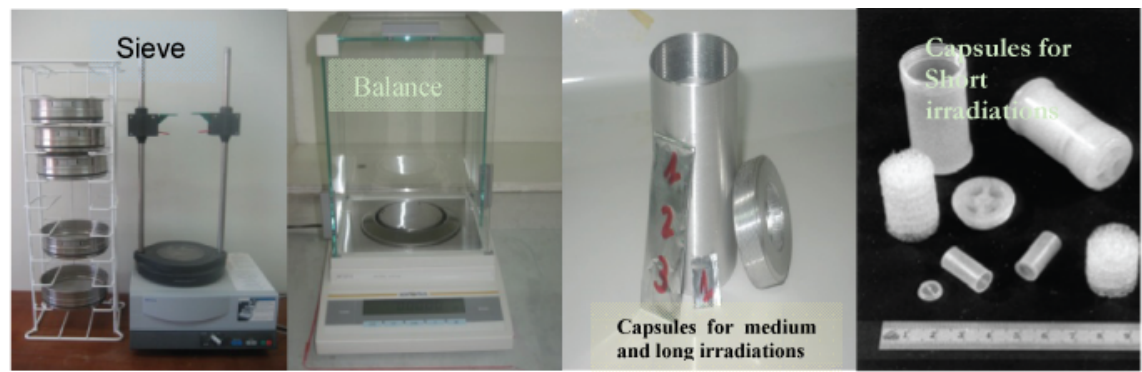

Figure 3. Some instruments and materials used for the sample preparation.

\begin{tabular}{llll}
\hline method & $\mathbf{a}$ & $\mathbf{f}$ & $\boldsymbol{r}(\boldsymbol{a}) \sqrt{\boldsymbol{T}_{\boldsymbol{n}} / \boldsymbol{T}_{\mathbf{0}}}$ \\
\hline Cd-ratio & $0.026 \pm 0.012$ & $28.4 \pm 1.6$ & $0.038 \pm 0.004$ \\
\hline Cd-covered & $0.024 \pm 0.010$ & $28.7 \pm 2.1$ & - \\
\hline Bare triple monitor & $0.030 \pm 0.008$ & $28.6 \pm 1.8$ & - \\
\hline Bare bi-isotopic & - & $29.5 \pm 2.5$ & $0.036 \pm 0.003$ \\
\hline Average & $0.027 \pm 0.010$ & $28.8 \pm 2.0$ & $0.037 \pm 0.003$ \\
\hline
\end{tabular}

Table 1. The parameters $a, f$ and $r(a) \sqrt{T_{n} / T_{0}}$ obtained by different methods.

\begin{tabular}{llllll}
\hline parameter & $\mathbf{a}$ & $\mathbf{f}$ & $\operatorname{Tn}\left({ }^{\circ} \mathrm{C}\right)$ & $\operatorname{Rcd}(\mathrm{Au})$ & $\boldsymbol{r}(\boldsymbol{a}) \sqrt{T_{n} / \boldsymbol{T}_{0}}$ \\
\hline Measured value & $0.027 \pm 0.010$ & $28.8 \pm 2.0$ & $34 \pm 1.8$ & $2.93 \pm 0.32$ & $0.037 \pm 0.003$ \\
\hline
\end{tabular}

Table 2. Neutron spectrum parameters in the irradiation site at es-Salam research reactor.

Step 3: after the irradiation the measurement is performed after a suitable cooling time $\left(t_{c}\right)$. In NAA, nearly exclusively the (energy of the) gamma radiation is measured because of its higher penetrating power of this type of radiation, and the selectivity that can be obtained from distinct energies of the photons - differently from beta radiation which is a continuous energy distribution. The interaction of gamma- and X-radiation with matter results, among others, in ionization processes and subsequent generation of electrical signals (currents) that can be detected and recorded.

The instrumentation used to measure gamma rays from radioactive samples generally consists of a semiconductor detector, associated electronics, and a computer-based multi-channel analyzer (MCA/computer). 


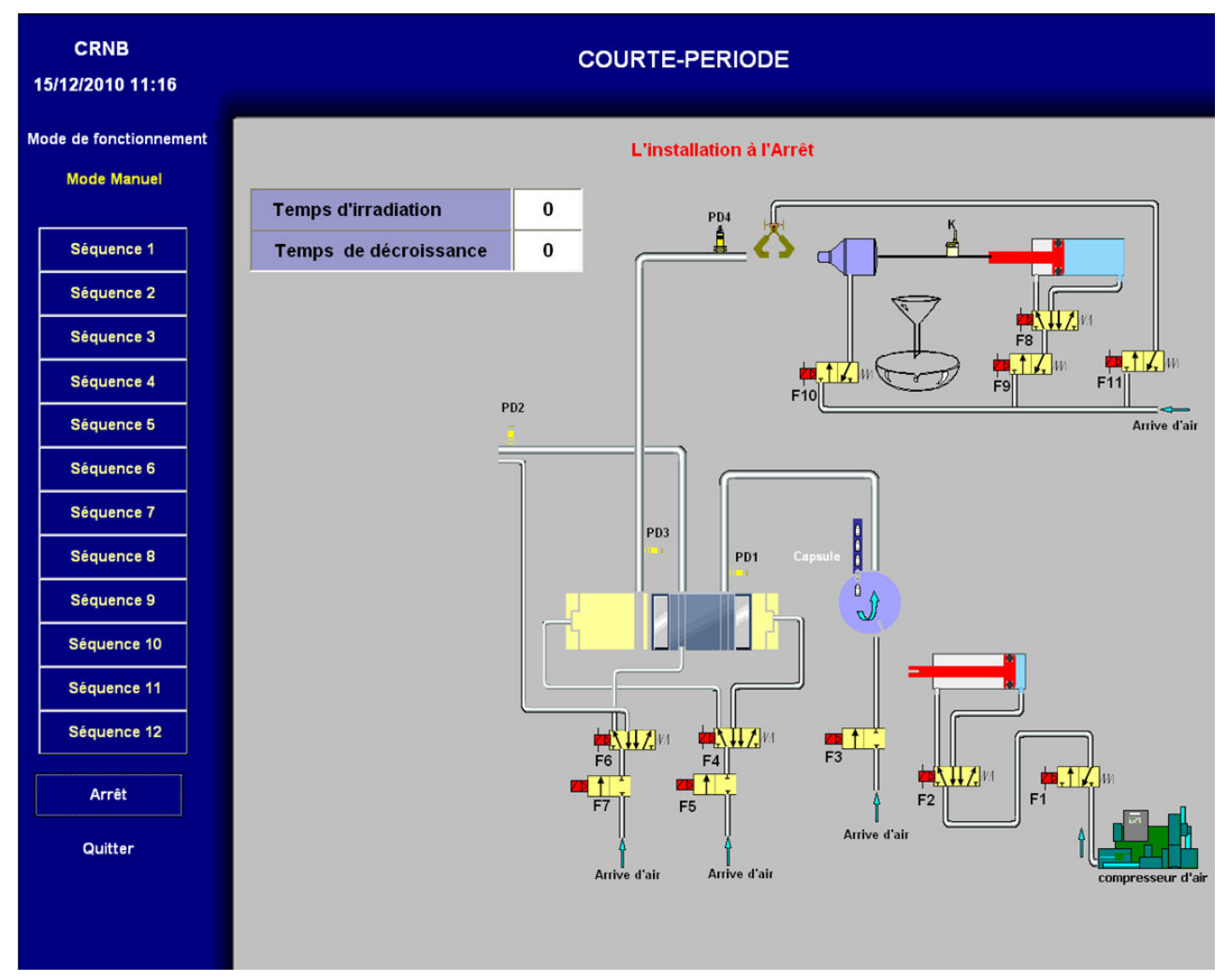

Figure 4. Pneumatic system for short irradiations using a thermal neutron flux at Es-Salam research reactor.

Most NAA labs operate one or more hyper-pure germanium (HPGe) detectors, which operate at liquid nitrogen temperature $(77 \mathrm{~K})$. Although HPGe detectors come in many different shapes and sizes, the most common shape is coaxial. These detectors are very useful for measurement of gamma rays with energies in the range from about $60 \mathrm{keV}$ to $3.0 \mathrm{MeV}$. The two most important characteristics a HPGe detector are its resolution and efficiency. Other characteristics to consider are peak shape, peak-to-Compton ratio, pulse rise time, crystal dimensions or shape, and price. The detector's resolution is a measure of its ability to separate closely spaced peaks in the spectrum, and, in general, the resolution is specified in terms of the full width at half maximum (FWHM) of the $122 \mathrm{keV}$ photopeak of ${ }^{57} \mathrm{Co}$ and the 1,332 $\mathrm{keV}$ photopeak of ${ }^{60} \mathrm{Co}$. For most NAA applications, a detector with $0.5 \mathrm{keV}$ resolution or less at $122 \mathrm{keV}$ and $1.8 \mathrm{keV}$ or less at 1,332 keV is sufficient. Detector efficiency for a given 
detector depends on gamma-ray energy and the sample and detector geometry, i.e. subtended solid angle. Of course, a larger volume detector will have a higher efficiency.

At Es-Salam NAA Lab, four gamma-ray spectrometers of Canberra for which one of them consists of a HPGe detector 35\% relative efficiency connected with Genie 2k Inspector and the three other spectrometers are composed of detectors (30, 35 and $45 \%$ relative efficiency) connected with a three Lynx® Digital Signal Analyser, It is a 32K channel integrated signal analyzer based on advanced digital signal processing (DSP) techniques. All spectrometers operate with Genie ${ }^{\mathrm{TM}} 2000$ spectroscopy software. A radiation detector therefore consists of an absorbing material in which at least part of the radiation energy is converted into detectable products, and a system for the detection of these products. Figure 5 illustrates Gammaray spectroscopy systems. The detectors are kept at liquid nitrogen temperatures (dewers under cave). The boxes in the left and in the right of the computer are the Lynx Digital Spectrometer Processing.

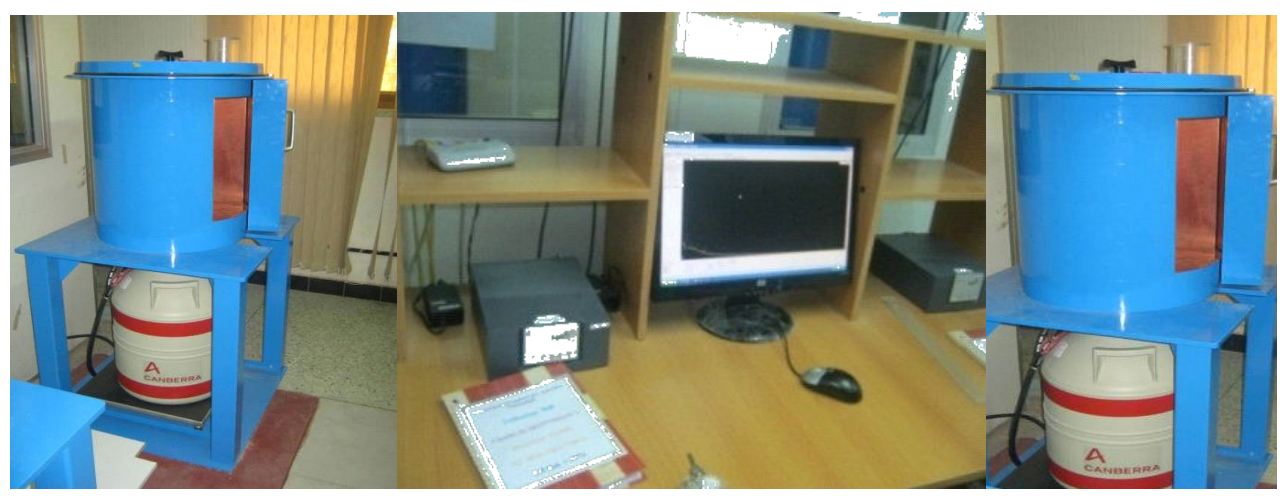

Figure 5. Gamma-ray spectroscopy systems in NAA/CRNB laboratory.

Step 5: Measurement, evaluation and calculation involve taking the gamma spectra and the calculating trace element concentrations of the sample and preparation of the NAA report.

In this part of work, Peter bode describes clearly in his paper [1] the analysis procedure of gamma-spectrum to the determination of the amount of element in sample. The acquisition of gamma spectrum Fig.6 and Fig.7 via the spectroscopy system Fig. 5 is analyzed to identify the radionuclides produced and their amounts of radioactivity in order to derive the target elements from which they have been produced and their masses in the activated sample. The spectrum analysis starts with the determination of the location of the (centroids of the) peaks. Secondly, the peaks are fitted to obtain their precise positions and net peak areas. The Analytical protocol adopted in our NAA laboratory is presented in Fig.8. 


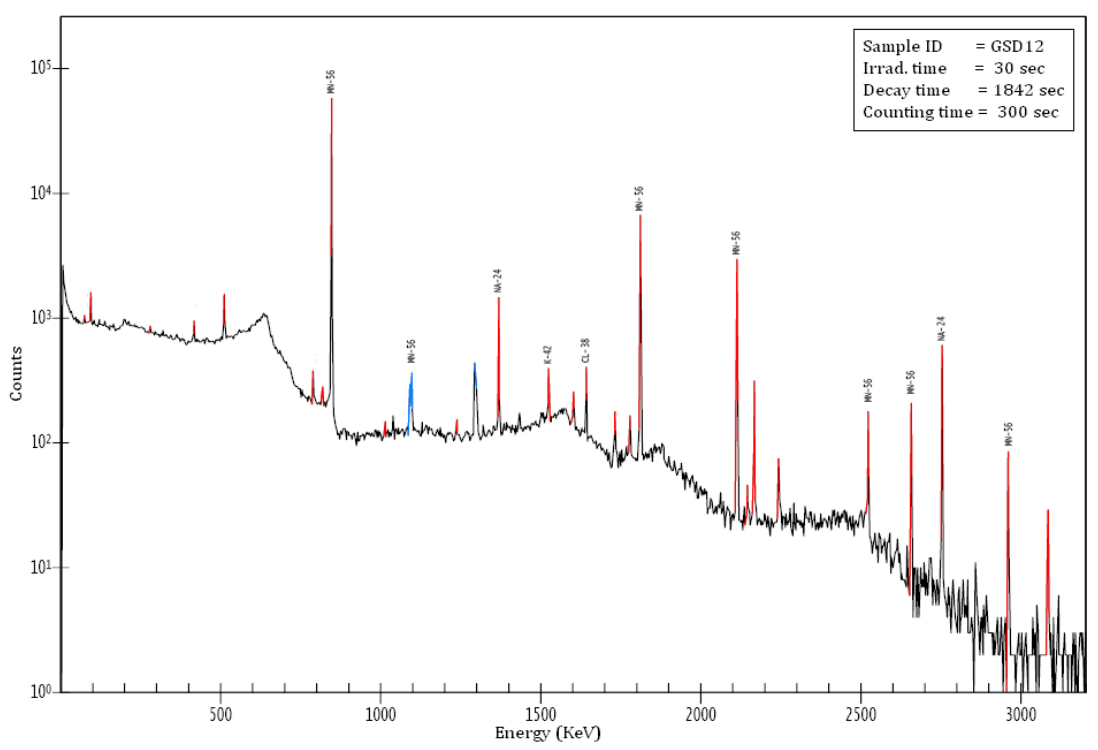

Figure 6. Gamma-ray spectrum showing several short-lived elements measured in a CRM-DSD-12 standard irradiated at Es-salam research reactor for 30 seconds, decayed for 30.7 minutes, and counted for 5 minutes with an HPGe detector.

The positions - often expressed as channel numbers of the memory of a multi-channel pulse height analyzer - can be converted into the energies of the radiation emitted; this is the basis for the identification of the radioactive nuclei. On basis of knowledge of possible nuclear reactions upon neutron activation, the (stable) element composition is derived. The values of the net peak areas can be used to calculate the amounts of radioactivity of the radionuclides using the full energy photopeak efficiency of the detector.

The amounts (mass) of the elements may then be determined if the neutron fluence rate and cross sections are known. In the practice, however, the masses of the elements are determined from the net peak areas by comparison with the induced radioactivity of the same neutron activation produced radionuclides from known amounts of the element of interest. The combination of energy of emitted radiation, relative intensities if photons of different energies are emitted and the half life of the radionuclide is unique for each radionuclide, and forms the basis of the qualitative information in NAA. The amount of the radiation is directly proportional to the number of radioactive nuclei produced (and decaying), and thus with the number of nuclei of the stable isotope that underwent the nuclear reaction. It provides the quantitative information in NAA. 

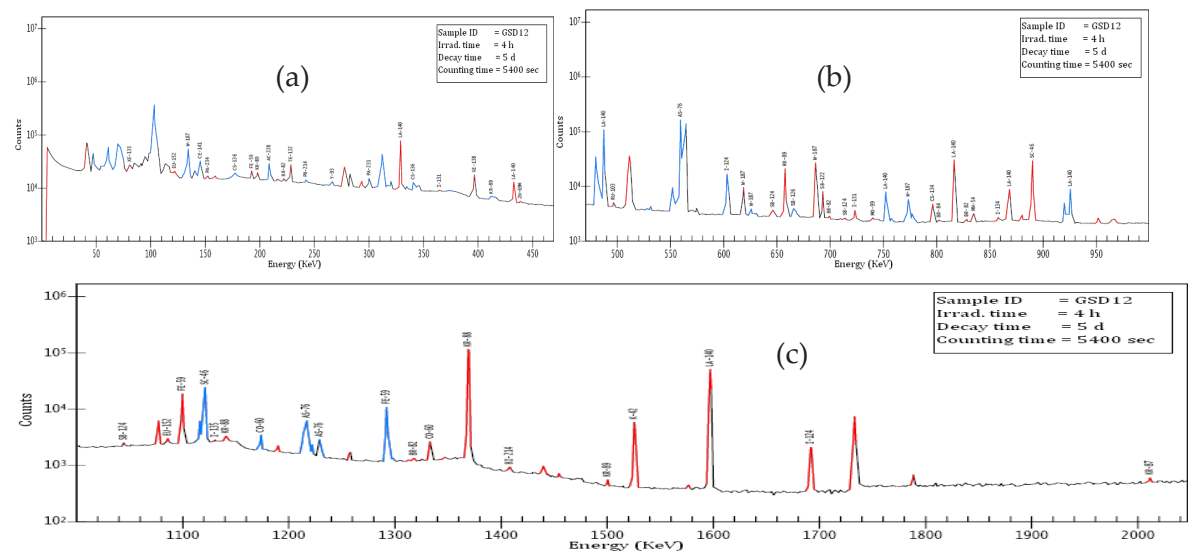

Figure 7. Gamma-ray spectrum (a) from 0 to $450 \mathrm{keV}$, (b) from 450 to $1000 \mathrm{keV}$ and (c) from 1000 to $2000 \mathrm{keV}$ : showing medium- and long-lived elements measured in a sample of CRM-GSD-12 standard irradiated at Es-salam research reactor for 4 hours, decayed for 5 days, and counted for 90 minutes on a HPGe detector.

The measured in NAA - the quantity intended to be measured - is the total mass of a given element in a test portion of a sample of a given matrix in all physico-chemical states. The quantity 'subject to measurement' is the number of disintegrating nuclei of a radionuclide. The measurement results in the number of counts in a given period of time, from which the disintegration rate and the number of disintegrating nuclei is calculated; the latter number is directly proportional to the number of nuclei of the stable isotope subject to the nuclear reaction, and thus to the number of nuclei of the element, which finally provides information on the mass and amount of substance of that element (see Eq. 16). An example of typical ranges of experimental conditions is given in Table 3 [1].

In practice, our laboratory proceeds in the treatment of spectra and calculation of elemental concentrations of analyzed samples according the approach illustrated in figure 8 . 


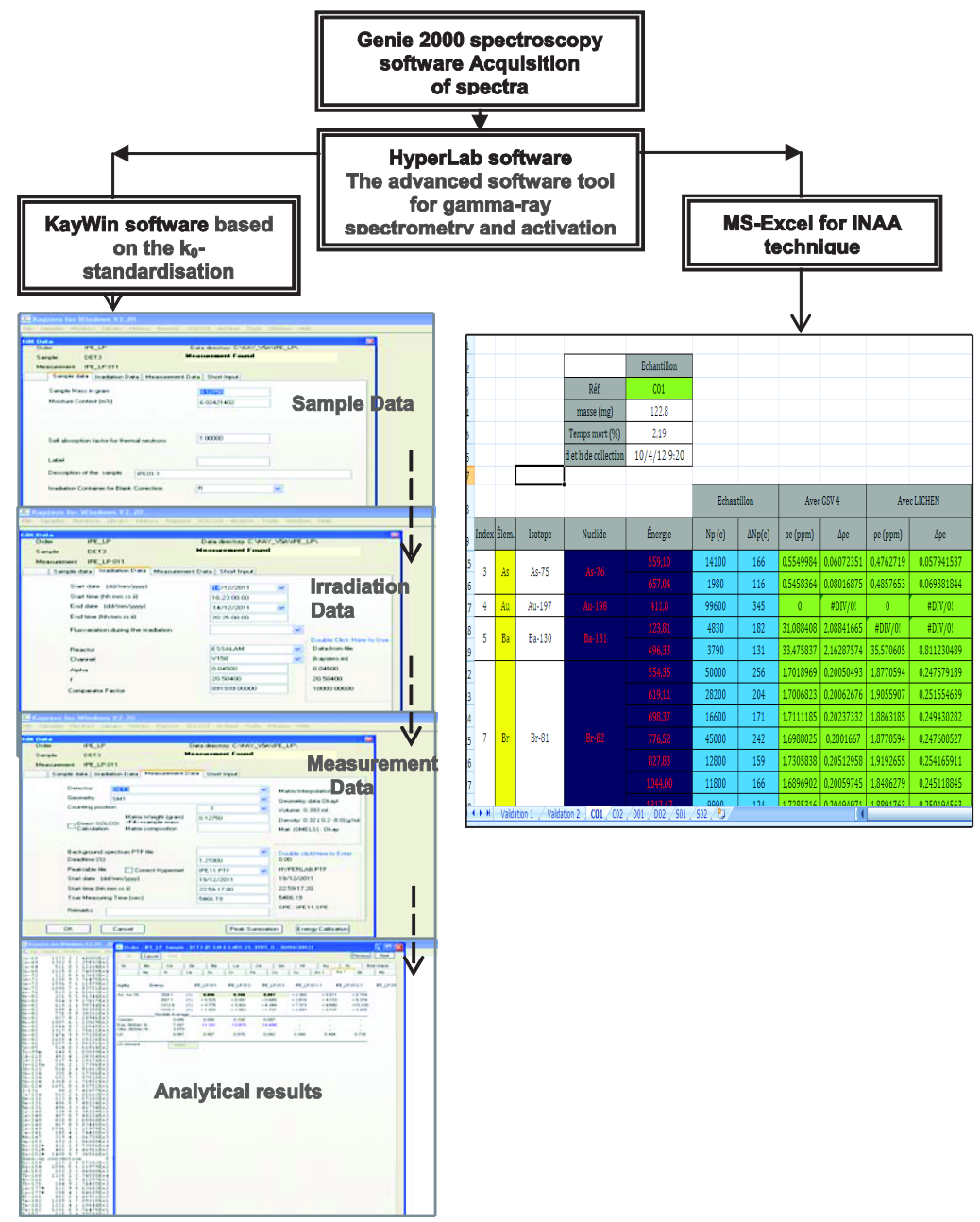

Figure 8. Analytical protocol adopted in NAA/CRNB laboratory [13].

\begin{tabular}{llll}
\hline \multicolumn{2}{l}{ Test portion mass : $5-500 \mathrm{mg}$} \\
\hline Neutron fluence rates available $10^{16}-10^{18} \mathrm{~m}^{-2} \mathrm{~s}^{-1}$ & & \\
\hline Irradiation & Decay & Measurement & Analyzed element \\
\hline $5-30$ seconds & $5-600$ seconds & $15-300$ seconds & Short lived \\
\hline $1-8$ hours & $3-5$ days & $1-4$ hours & Medium lived \\
\cline { 2 - 4 } & 20 days & $1-16$ hours & Long lived \\
\hline
\end{tabular}

Table 3. Example of typical ranges of experimental conditions of an INAA procedure. 


\subsection{Derivation of the measurement equation}

The reaction rate $\mathrm{R}$ per nucleus capturing a neutron is given by:

$$
R=\int_{0}^{\infty} \sigma(v) \phi^{\prime}(v) d v=\int_{0}^{\infty} \sigma(E) \phi^{\prime}(E) d E=\int_{0}^{\infty} n^{\prime}(v) v \sigma(v) d v,
$$

where:

$\sigma(\mathrm{v})$ is the $(\mathrm{n}, \gamma)$ cross section (in $\mathrm{cm}^{2} ; 1$ barn $(\mathrm{b})=10^{-24} \mathrm{~cm}^{2}$ ) at neutron velocity $\mathrm{v}\left(\right.$ in $\left.\mathrm{cm} \mathrm{s}^{-1}\right)$;

$\sigma(\mathrm{E})$ is the $(\mathrm{n}, \gamma)$ cross section $\left(\right.$ in $\left.\mathrm{cm}^{2}\right)$ at neutron energy $\mathrm{E}$ (in $\left.\mathrm{eV}\right)$;

$\Phi^{\prime}(\mathrm{v})$ is the neutron flux per unit of velocity interval $\left(\right.$ in $\left.\mathrm{cm}^{-3}\right)$ at neutron velocity $\mathrm{v}$;

$\mathrm{n}^{\prime}(\mathrm{v})$ is the neutron density per unit of velocity interval $\left(\mathrm{in}^{-4} \mathrm{~s}\right)$ at neutron velocity $\mathrm{v}$;

$\Phi^{\prime}(\mathrm{E})$ is the neutron flux per unit of energy interval (in $\left.\mathrm{cm}^{-2} \mathrm{~s}^{-1} \mathrm{eV}^{-1}\right)$ at neutron energy $\mathrm{E}$.

In Eq.(1), $\sigma(\mathrm{v})=\sigma(\mathrm{E})$ with $\mathrm{E}$ (in erg $\left.=6.2415 .10^{11} \mathrm{eV}\right)=1 / 2 \mathrm{~m}_{\mathrm{n}} \mathrm{v}^{2}\left[\mathrm{~m}_{\mathrm{n}}\right.$ rest mass of the neutron $=1.674910^{-24} \mathrm{~g}$ ]. Furthermore, per definition, $\varphi^{\prime}(\mathrm{v}) \mathrm{dv}=\varphi^{\prime}(\mathrm{E}) \mathrm{dE}\left(\right.$ both in $\mathrm{cm}^{-2} \mathrm{~s}^{-1}$ ).

In Eq.1, the functions $\sigma(\mathrm{v})[=\sigma(\mathrm{E})]$ and $\varphi^{\prime}(\mathrm{v})\left[\varphi^{\prime}(\mathrm{E})\right]$ are complex and are respectively depending on the $(n, \gamma)$ reaction and on the irradiation site.

In 1987, F De Corte describes in his Aggregate thesis "Chapter 1: fundamentals [3] that the introduction of some generally valid characteristics yields the possibility of avoiding the actual integration and describing accurately the reaction rate in a relatively simple way by means of so-called formalisms or conventions. In short, these characteristics are:

In nuclear research reactors - which are intense sources of neutrons - three types of neutrons can be distinguished. The neutron flux distribution can be divided into three components (see Figure 9):

1. Fission or fast neutrons released in the fission of 235U. Their energy distribution ranges from $100 \mathrm{keV}$ to $25 \mathrm{MeV}$ with a maximum fraction at $2 \mathrm{MeV}$. These neutrons are slowed down by interaction with a moderator, e.g. $\mathrm{H} 2 \mathrm{O}$, to enhance the probability of them causing a fission chain reaction in the $235 \mathrm{U}$.

2. The epithermal neutron component consists of neutrons (energies from $0.5 \mathrm{eV}$ to about $100 \mathrm{keV}$ ). A cadmium foil $1 \mathrm{~mm}$ thick absorbs all thermal neutrons but will allow epithermal and fast neutrons above $0.5 \mathrm{eV}$ in energy to pass through. Both thermal and epithermal neutrons induce $(n, \gamma)$ reactions on target nuclei.

3. The thermal neutron component consists of low-energy neutrons (energies below 0.5 $\mathrm{eV}$ ) in thermal equilibrium with atoms in the reactor's moderator. At room temperature, the energy spectrum of thermal neutrons is best described by a Maxwell-Boltzmann distribution with a mean energy of $0.025 \mathrm{eV}$ and a most probable velocity of $2200 \mathrm{~m} / \mathrm{s}$. In general, a $1 \mathrm{MW}$ reactor has a peak thermal neutron flux of approximately $10^{13} \mathrm{n} / \mathrm{cm}^{2}$. 
The $(\mathrm{n}, \gamma)$ cross section function, $\sigma(\mathrm{v})$ versus $\mathrm{v}$ can be interpreted as a $\sigma(\mathrm{v}) \sim 1 / \mathrm{v}$ dependence, or $\sigma(E) \sim 1 / E^{1 / 2}$ dependence [ $\log \sigma(E)$ versus $\log E$ is linear with slope $-1 / 2$ ], on which (above some $\mathrm{eV}$ ) several resonances are superposed see Figure 10 taken from http://thorea.wikia.com/wiki/Thermal,_Epithermal_and_Fast_Neutron_Spectra web page.

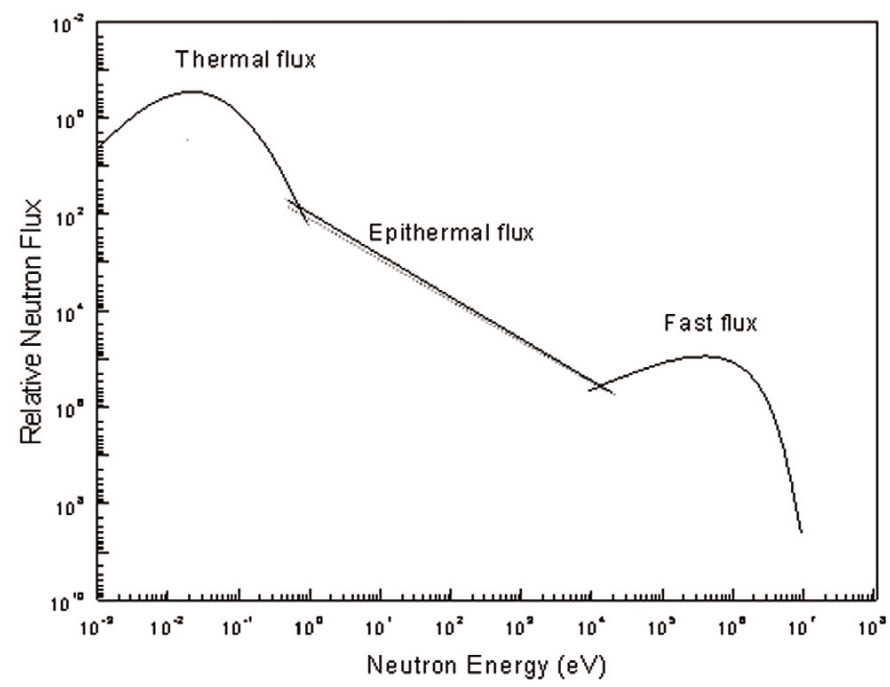

Figure 9. A typical reactor neutron energy spectrum showing the various components used to describe the neutron energy regions.

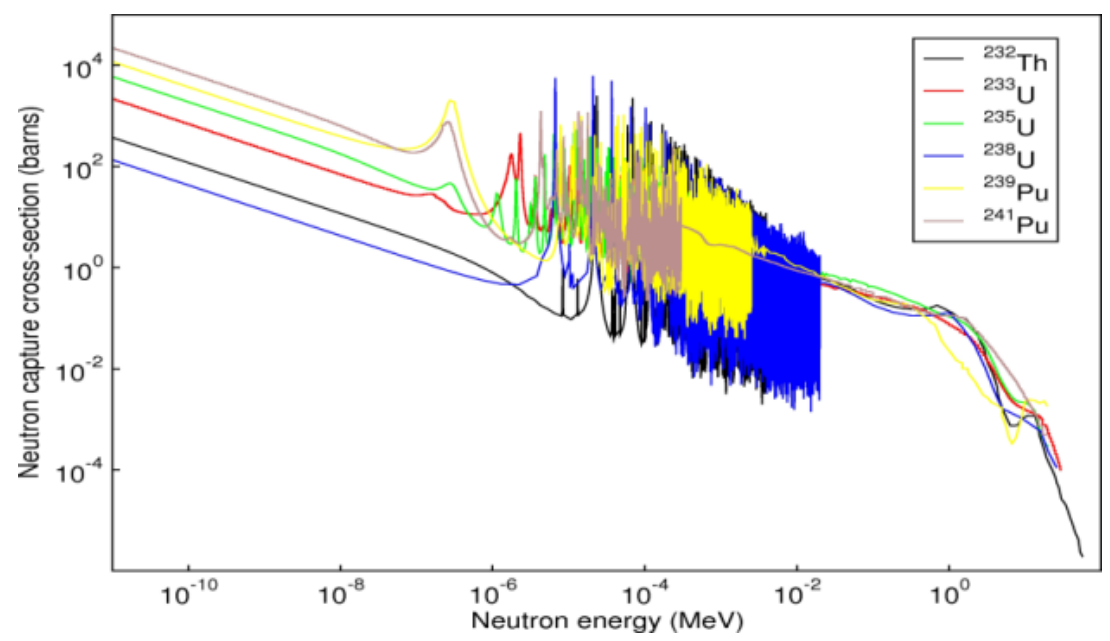

Figure 10. Relation between neutron cross section and neutron energy for major actinides ( $\mathrm{n}$, capture). 
An NAA technique that employs only epithermal neutrons to induce $(n, \gamma)$ reactions by irradiating the samples being analyzed inside either cadmium or boron a shield is called epithermal neutron activation analysis (ENAA).

The production of radioactive nuclei is described by:

$$
\frac{d N}{d t}=R N_{0}-\lambda N
$$

In which $\mathrm{N}_{0}$ number of target nuclei, $\mathrm{N}$ is the number of radioactive nuclei, $\lambda$ is the decay constant in $\mathrm{s}^{-1}$. The disintegration rate of the produced radionuclide at the end of the irradiation time ti follows from:

$$
D\left(t_{i}\right)=N\left(t_{i}\right) \lambda=N_{0} R\left(1-e^{-\lambda t_{i}}\right)
$$

where:

$\mathrm{D}$ is the disintegration rate in $\mathrm{Bq}$ of the produced radionuclide, assuming that $\mathrm{N}=0$ at $\mathrm{t}=0$ and $\mathrm{N} 0=$ constant.

The dependence of the activation cross section and neutron fluence rate to the neutron energy can be taken into account in Eq. (1) by dividing the neutron spectrum into a thermal and an epithermal region; the division is made at $\mathrm{En}=0.55 \mathrm{eV}$ (the so-called cadmium cut-off energy). This approach is commonly known as the Høgdahl convention [4].

The integral in Eq. (1) can then be rewritten as:

$$
R=\int_{0}^{v_{C d}} n(v) v \sigma(v) d v+\int_{v_{C d}}^{\infty} n(v) v \sigma(v) d v
$$

The first term can be integrated straightforward:

$$
\int_{0}^{v_{C d}} n(v) v d v=v_{0} \sigma_{0} \int_{0}^{v_{C d}} n(v) d v=\mathrm{nv}_{0} \sigma_{0}
$$

in which,

$$
n=\int_{0}^{v_{C d}} n(v) d v
$$


is called the thermal neutron density, with $\Phi_{\mathrm{th}}=\mathrm{nv}_{0}$,

- $\Phi_{\text {th }}$ is the conventional thermal neutron fluence rate, $\mathrm{m}^{-2} \mathrm{~s}^{-1}$, for energies up to the Cd cutoff energy of $0.55 \mathrm{eV}$;

- $\sigma_{0}$ is the thermal neutron activation cross section, $\mathrm{m}^{2}$, at $0.025 \mathrm{eV}$;

- $\mathrm{v}_{0}$ is the most probable neutron velocity at $20^{\circ} \mathrm{C}: 2200 \mathrm{~m} \mathrm{~s}^{-1}$.

The second term is re-formulated in terms of neutron energy rather than neutron velocity and the infinite dilution resonance integral $\mathrm{I}_{0}-$ which effectively is also a cross section $\left(\mathrm{m}^{2}\right)$ is introduced:

$$
\int_{v_{C d}}^{\infty} n(v) v d v=\varphi_{\text {epi }} \int_{E_{\mathrm{Cd}}}^{\mathrm{E}_{\max }} \frac{\sigma\left(\mathrm{E}_{\mathrm{n}}\right) d E_{n}}{E_{n}}=\varphi_{\text {epi }} I_{0}
$$

with:

$$
I_{0}=\int_{\mathrm{E}_{\mathrm{Cd}}}^{\mathrm{E}_{\max }} \frac{\sigma\left(\mathrm{E}_{\mathrm{n}}\right) d E_{n}}{E_{n}}
$$

Here, $\Phi_{\text {epi }}$ the conventional epithermal neutron fluence rate per unit energy interval, at $1 \mathrm{eV}$.

From this definition of $\mathrm{I}_{0}$ it can be seen that it assumes that the energy dependency of the epithermal neutron fluence rate is proportional to $1 / \mathrm{En}$. This requirement is fulfilled to a good approximation by most of the $(n, \gamma)$ reactions.

In the practice of nuclear reactor facilities the epithermal neutron fluence rate Фepi is not precisely following the inverse proportionality to the neutron energy; the small deviation can be accounted for by introducing an epithermal fluence rate distribution parameter $\alpha$ :

$$
I_{0}(\alpha)=(1 \mathrm{eV})^{\alpha} \int_{\mathrm{E}_{\mathrm{Cd}}}^{\mathrm{E}_{\max }} \frac{\sigma\left(\mathrm{E}_{\mathrm{n}}\right) d E_{n}}{E_{n}^{(1+\alpha)}}
$$

The expression for the reaction rate can thus be re-written as:

$$
R=\varphi_{t h} \sigma_{0}+\varphi_{\text {epi }} I_{0}(\alpha)
$$

Expressing the ratio of the thermal neutron fluence rate and the epithermal neutron fluence rate as $\mathrm{f}=\Phi_{\mathrm{th}} / \Phi_{\text {epi }}$ and the ratio of the resonance integral and the thermal activation cross section as $\mathrm{Q}_{0}(\alpha)=\mathrm{I}_{0}(\alpha) / \sigma_{0}$, an effective cross section can be defined: 


$$
\sigma_{e f f}=\sigma_{0}\left(1+\frac{Q_{0}(\alpha)}{f}\right)
$$

It simplifies the Eq. (10) for the reaction rate to:

$$
R=\varphi_{\text {th }} \sigma_{\text {eff }}
$$

This reaction rate applies to infinite thin objects. In objects of defined dimensions, the inside part will experience a lower neutron fluence rate than the outside part because neutrons are removed by absorption.

The nuclear transformations are established by measurement of the number of nuclear decays. The number of activated nuclei $N\left(t_{i}, t_{d}\right)$ present at the start of the measurement is given by:

$$
N\left(t_{i}, t_{d}, t_{m}\right)=\frac{R N_{0}}{\lambda}\left(1-e^{-\lambda t_{i}}\right) e^{-\lambda t_{d}}
$$

and the number of nuclei $\Delta \mathrm{N}$ disintegrating during the measurement is given by:

$$
\Delta N\left(t_{i}, t_{d}, t_{m}\right)=\frac{R N_{0}}{\lambda}\left(1-e^{-\lambda t_{i}}\right) e^{-\lambda t_{d}}\left(1-\mathrm{e}^{-\lambda t_{\mathrm{m}}}\right)
$$

in which $t_{d}$ is the decay or waiting time, i.e. the time between the end of the irradiation and the start of the measurement $t_{m}$ is the duration of the measurement. Additional correction resulting from high counting rates may be necessary depending upon the gamma-ray spectrometer hardware used as illustrated in chapter 2 [1]. Replacing the number of target nuclei $\mathrm{N}_{0}$ by $\left(\mathrm{N}_{\mathrm{Av}} \mathrm{m}\right) / \mathrm{M}$ and using the Eq. (12) for the reaction rate, the resulting net counts $\mathrm{C}$ in a peak in the spectrum corresponding with a given photon energy is approximated by the activation formula:

$$
N_{p}=\Delta N \gamma \varepsilon=\varphi_{t h} \sigma_{e f f} \frac{N_{a v} \theta m_{x}}{M_{a}}\left(1-e^{-\lambda t_{i}}\right) e^{-\lambda t_{d}}\left(1-\mathrm{e}^{-\lambda t_{\mathrm{m}}}\right) \mathrm{I} \varepsilon
$$

with:

- $\mathrm{N}_{\mathrm{p}}$ is the net counts in the $\gamma$-ray peak of $\mathrm{E}_{\gamma}$;

- $\mathrm{N}_{\mathrm{Av}}$ is the Avogadro's number in $\mathrm{mol}^{-1}$;

- $\theta$ is isotopic abundance of the target isotope; 
- $\mathrm{m}_{\mathrm{x}}$ is the mass of the irradiated element in $\mathrm{g}$;

- $\mathrm{M}_{\mathrm{a}}$ is the atomic mass in $\mathrm{g} \mathrm{mol}^{-1}$;

- I is the gamma-ray abundance, i.e. the probability of the disintegrating nucleus emitting a photon of $\mathrm{E}_{\gamma}$ (photons disintegration ${ }^{-1}$ );

- $\varepsilon$ is the full energy photopeak efficiency of the detector, i.e. the probability that an emitted photon of given energy will be detected and contribute to the photopeak at energy $E_{\gamma}$ in the spectrum.

Although the photons emitted have energies ranging from tens of keVs to MeVs and have high penetrating powers, they still can be absorbed or scattered in the sample itself depending on the sample size, composition and photon energy. This effect is called gamma-ray selfattenuation. Also, two or more photons may be detected simultaneously within the time resolution of the detector; this effect is called summation.

Eq. (15) can be simply rewritten towards the measurement equation of NAA, which shows how the mass of an element measured can be derived from the net peak area C:

$$
m_{x}=N_{p} \cdot \frac{M_{a}}{N_{a v} \cdot \theta} \cdot \frac{\lambda}{\varphi_{t h} \cdot \sigma_{e f f} \cdot \mathrm{I} \cdot \varepsilon \cdot\left(1-e^{-\lambda t_{i}}\right) \cdot e^{-\lambda t_{d}} \cdot\left(1-\mathrm{e}^{-\lambda \mathrm{t}_{\mathrm{m}}}\right)}
$$

\subsection{Standardization}

Standardization is based on the determination of the proportionality factors $\mathrm{F}$ that relate the net peak areas in the gamma-ray spectrum to the amounts of the elements present in the sample under given experimental conditions:

$$
F=\frac{N_{p}}{M}
$$

Both absolute and relative methods of calibration exist.

\subsubsection{Absolute calibration}

The values of the physical parameters determining the proportionality factor $\theta, N_{A v}, M, \sigma_{\text {eff }}$ $\mathrm{I}, \lambda$, are taken from literature. The parameters $\sigma_{\text {eff }}$ respectively $\mathrm{I}, \lambda$ are not precisely known for many $(n, \gamma)$ reactions and radionuclides, and in some cases $\theta$ is also not accurately known. Since the various parameters were often achieved via independent methods, their individual uncertainties will add up in the combined uncertainty of measurement of the elemental amounts, leading to a relatively large combined standard uncertainty. Moreover, the metrological traceability of the values of the physical constants is not known for all radionuclides. The other parameters $\mathrm{N}_{\mathrm{p}}, \mathrm{m}_{\mathrm{x}}, \Phi, \varepsilon, \mathrm{t}_{\mathrm{i}}, \mathrm{t}_{\mathrm{d}}, \mathrm{t}_{\mathrm{m}}$ are determined, calculated or measured for the given circumstances and uncertainties can be established. 


\subsubsection{Relative calibration}

a. Direct comparator method

The unknown sample is irradiated together with a calibrator containing a known amount of the element(s) of interest. The calibrator is measured under the same conditions as the sample (sample-to-detector distance, equivalent sample size and if possible equivalent in composition). From comparison of the net peak areas in the two measured spectra the mass of the element of interest can be calculated:

$$
m_{x(\text { unk })}=m_{x(\text { cal })} \cdot \frac{\left(\frac{N_{p}}{t_{m} \cdot e^{-\lambda t_{d}} \cdot\left(1-e^{-\lambda t_{m}}\right)}\right)_{u n k}}{\left(\frac{N_{p}}{t_{m} \cdot e^{-\lambda t_{d}} \cdot\left(1-e^{-\lambda t_{m}}\right)}\right)_{c a l}}
$$

in which $m_{x}$ (unk), $m_{x}($ cal $)$ mass of the element of interest, in the unknown sample and the calibrator, respectively in $\mathrm{g}$.

In this procedure many of the experimental parameters - such as neutron fluence rate, cross section and photopeak efficiency cancel out at the calculation of the mass and the remaining parameters are all known. This calibration procedure is used if the highest degree of accuracy is required.

The relative calibration on basis of element calibrators is not immediately suitable for laboratories aiming at the full multi-element powers of INAA. It takes considerable effort to prepare multi-element calibrators for all 70 elements measurable via NAA with adequate degree of accuracy in a volume closely matching the size and the shape of the samples. Single comparator method Multi-element INAA on basis of the relative calibration method is feasible when performed according to the principles of the single comparator method. Assuming stability in time of all relevant experimental conditions, calibrators for all elements are co-irradiated each in turn with the chosen single comparator element. Once the sensitivity for all elements relative to the comparator element has been determined (expressed as the so-called k-factor, see below), only the comparator element has to be used in routine measurements instead of individual calibrators for each element. The single comparator method for multi-element INAA was based on the ratio of proportionality factors of the element of interest and of the comparator element after correction for saturation, decay, counting and sample weights defined the $\mathrm{k}$-factor for each element $\mathrm{i}$ as:

$$
k_{i}=\frac{\left(M_{a}\right)_{i, c a l} \gamma_{c o m p} \varepsilon_{c o m p} \theta_{c o m p} \sigma_{e f f, c o m p}}{M_{i, c a l} \gamma_{i, c a l} \varepsilon_{i, c a l} \theta_{i, c a l}\left(\sigma_{e f f}\right)_{i, c a l}}
$$


Masses for each element $i$ then can be calculated from these $k_{i}$ factors; for an element determined via a directly produced radionuclide the mass $m_{x}(u n k)$ follows from:

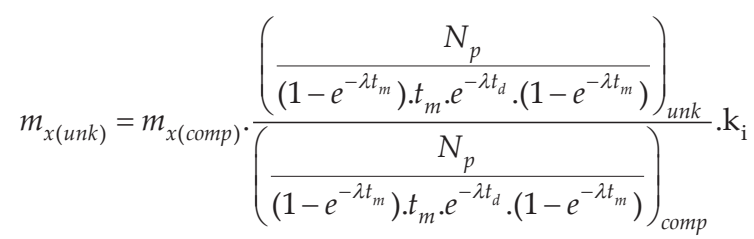

where: $\mathrm{m}_{\mathrm{x}}(\mathrm{comp})$ is the mass of element $\mathrm{x}$ in comparator in $\mathrm{g}$.

These experimentally determined k-factors are often more accurate than when calculated on basis of literature data as in the absolute calibration method. However, the k-factors are only valid for a specific detector, a specific counting geometry and irradiation facility, and remain valid only as long as the neutron fluence rate parameters of the irradiation facility remain stable. The single comparator method requires laborious calibrations in advance, and finally yield relatively (compared to the direct comparator method) higher uncertainties of the measured values. Moreover, it requires experimental determination of the photopeak efficiencies of the detector. Metrological traceability of the measured values to the S.I. may be demonstrated.

b. The $\mathrm{k}_{0}$-comparator method

The $k_{0}$-based neutron activation analysis $\left(k_{0}\right.$-NAA) technique, developed in $1970 \mathrm{~s}$, is being increasingly used for multielement analysis in a variety of matrices using reactor neutrons [4-10]. In our research reactor, the $k_{0}$-method was successfully developed using the Høgdahl formalism [11]. In the $k 0$-based neutron activation analysis the evaluation of the analytical result is based on the so-called $k_{0}$ - factors that are associated with each gammaline in the gamma-spectrum of the activated sample. These factors replace nuclear constants, such as cross sections and gamma-emission probabilities, and are determined in specialized NAA laboratories. This technique has been reported to be flexible with respect to changes in irradiation and measuring conditions, to be simpler than the relative comparator technique in terms of experiments but involves more complex formulae and calculations, and to eliminate the need for using multielement standards. The $k_{0}$-NAA technique, in general, uses input parameters such as (1) the epithermal neutron flux shape factor $(\alpha)$, (2) subcadmium-to-epithermal neutron flux ratio $(f)$, (3) modified spectral index $r(\alpha) \sqrt{T_{n} / T_{0}}$, (4) Westcott's $g\left(T_{n}\right)$-factor, (5) the full energy peak detection efficiency $\left(\varepsilon_{p}\right)$, and (6) nuclear data on $Q_{0}$ (ratio of resonance integral $\left(I_{0}\right)$ to thermal neutron cross section $\left(\sigma_{0}\right)$ and $k_{0}$. The parameters from (1) to (4) are dependent on each irradiation facility and the parameter (5) is dependent on each counting facility. The neutron field in a nuclear reactor contains an epithermal component that contributes to the sample neutron activation [12]. Furthermore, for nuclides with the Westcott's $g\left(T_{n}\right)$-factor different from unity, the Høgdahl convention should not be applied and the neutron temperature should be in- 
troduced for application of a more sophisticated formalism [14], the Westcott formalism. These two formalisms should be taken into account in order to preserve the accuracy of $k_{0}$-method.

The $k_{0}$-NAA method is at present capable of tackling a large variety of analytical problems when it comes to the multi-element determination in many practical samples. In this part, we have published a paper [15] for which the determination of the Westcott and Høgdahl parameters have been carried out to assess the applicability of the $k_{0}$-NAA method using the experimental system and irradiation channels at Es-Salam research reactor.

During the three last decades Frans de Corte and his co-workers focused their investigations to develop a method based on co-irradiation of a sample and a neutron flux monitor, such as gold and the use of a composite nuclear constant called $\mathrm{k}_{0}$-factor $[3,16]$. In addition, this method allows to analyze the sample without use the reference standard like INAA method. The k-factors have been defined as independent of neutron fluence rate parameters as well as of spectrometer characteristics. In this approach, the irradiation parameter $\left(1+\mathrm{Q}_{0}(\alpha) / \mathrm{f}\right)(\mathrm{Eq}$. (11)) and the detection efficiency $\varepsilon$ are separated in the expression (19) of the k-factor, which resulted at the definition of the $\mathrm{k}_{0}$-factor.

$$
\begin{gathered}
k_{0}=\frac{1}{k} \cdot \frac{1+\mathrm{Q}_{0, \text { comp }}(\alpha) / f}{1+\mathrm{Q}_{0, \text { cal }}(\alpha) / f} \cdot \frac{\varepsilon_{\text {comp }}}{\varepsilon_{\text {comp }}}=\frac{\mathrm{M}_{\text {comp }}}{\theta_{\text {comp }} \sigma_{0, \text { comp }} \gamma_{\text {comp }}} \cdot \frac{\theta_{c a l} \sigma_{0, \text { cal }} \gamma_{c a l}}{\mathrm{M}_{\text {cal }}} \\
m_{x(\text { unk })}=m_{x(\text { comp })} \frac{1+\mathrm{Q}_{0, \text { comp }}(\alpha) / f}{1+\mathrm{Q}_{0, \text { cal }}(\alpha) / f} \cdot \frac{\varepsilon_{\text {comp }}}{\varepsilon_{\text {comp }}} \frac{\left(\frac{\mathrm{N}_{\mathrm{p}} / \mathrm{t}_{\mathrm{m}}}{\left(1-\mathrm{e}^{-\lambda \mathrm{t}_{\mathrm{i}}}\right) \cdot e^{-\lambda t_{d}}\left(1-e^{-\lambda t_{m}}\right) \cdot m}\right)_{\mathrm{unk}}}{\left(\frac{\mathrm{N}_{\mathrm{p}} / \mathrm{t}_{\mathrm{m}}}{\left(1-\mathrm{e}^{-\lambda \mathrm{t}_{\mathrm{i}}}\right) \cdot e^{-\lambda t_{d}}\left(1-e^{-\lambda t_{m}}\right) \cdot m}\right)_{\text {comp }}} \cdot \frac{1}{\mathrm{k}_{0}}
\end{gathered}
$$

The applicability of HØGDAHL convention is restricted to $(n, \gamma)$ reactions for which WESTCOTT's g-factor is equal to unity (independent of neutron temperature), the cases for which WESTCOTT's $g=1[3,4,17]$, such as the reactions ${ }^{151} \mathrm{Eu}(\mathrm{n}, \gamma)$ and ${ }^{176} \mathrm{Lu}(\mathrm{n}, \gamma)$ are excluded from being dealt with. Compared with relative method $\mathrm{k}_{0}$-NAA is experimentally simpler (it eliminates the need for multi-element standards [3, 18], but requires more complicated calculations [19]. In our research reactor, the $\mathrm{k}_{0}$-method was successfully developed using the HØGDAHL convention and WESTCOTT formalism [11, 15]. The $\mathrm{k}_{0}$-method requires tedious characterizations of the irradiation and measurement conditions and results, like the single comparator method, in relatively high uncertainties of the measured values of the masses. Moreover, metrological traceability of the currently existing $\mathrm{k}_{0}$ values and associated parameters to the S.I. is not yet transparent and most probably not possible. Summarizing, relative calibration by the direct comparator method renders the lowest uncertainties of the measured values whereas metrological traceability of these values to the S.I. can easily be demon- 
strated. As such, this approach is often preferred from a metrological viewpoint. The concentration of an element can be determined as:

$$
\rho_{x}(p p m)=\frac{\left[\frac{N_{p} / t_{m}}{S D C W}\right]_{x}}{\left[\frac{N_{p} / t_{m}}{S D C W}\right]_{A u}} \cdot \frac{1}{k_{0, A u(x)}} \cdot \frac{G_{t h, A u} f+G_{e p i, A u} Q_{0, A u}(\alpha)}{G_{t h, x} f+G_{e p i, x} Q_{0, x}(\alpha)} \cdot \frac{\varepsilon_{\mathrm{p}, \mathrm{Au}}}{\varepsilon_{\mathrm{p}, \mathrm{x}}} \times 10^{6}
$$

Where: the indices $x$ and Au refer to the sample and the monitor, respectively; $W_{A u}$ and $W_{x}$ represent the mass of the gold monitor and the sample (in $\mathrm{g}$ ); $\mathrm{N}_{\mathrm{p}}$ is the measured peak area, corrected for dead time and true coincidence; S, D, C are the saturation, decay and counting factors, respectively; tm is the measuring time; $G_{\text {th }}$ and $G_{e}$ are the correction factors for thermal and epithermal neutron self shielding, respectively.

\subsection{Sources errors}

Many publications reported in literature [20-25] treat the concept of evaluation of uncertainties in large range of analytical techniques.

We can give in this part of chapter, the evaluation of uncertainties for neutron activation analysis measurements. Among the techniques of standardization the comparator method for which the individual uncertainty components associated with measurements made with neutron activation analysis (NAA) using the comparator method of standardization (calibration), as well as methods to evaluate each one of these uncertainty components [1].

This description assumes basic knowledge of the NAA method, and that experimental parameters including sample and standard masses, as well as activation, decay, and counting times have been optimized for each measurement. It also assumes that the neutron irradiation facilities and gamma-ray spectrometry systems have been characterized and optimized appropriately, and that the choice of irradiation facility and detection system is appropriate for the measurement performed. Careful and thoughtful experimental design is often the best means of reducing uncertainties. The comparator method involves irradiating and counting a known amount of each element under investigation using the same or very similar conditions as used for the unknown samples. Summarizing, relative calibration by the direct comparator method renders the lowest uncertainties of the measured values whereas metrological traceability of these values to the S.I. can easily be demonstrated. As such, this approach is often preferred from a metrological viewpoint. The measurement equation can be further simplified, by substituting:

$$
A_{0}=\frac{\lambda N_{p} e^{\lambda t_{d}}}{\left(1-e^{-\lambda t_{m}}\right) \cdot\left(1-e^{-\lambda t_{i}}\right)} \cdot \mathrm{f}_{\mathrm{p}} \cdot \mathrm{f}_{\mathrm{ltc}}
$$

in : 


$$
m_{\text {unk }}=m_{\text {cal }} \frac{A_{0(\text { unk })}}{A_{0(\text { (cal })}} R_{\theta} R_{\Phi} R_{\sigma} R_{\varepsilon} \text {-blank }
$$

Where: $R_{\theta}$ is the ratio of isotopic abundances for unknown sample and calibrator, $R_{\phi}$ is the ratio of neutron fluence rates (including fluence gradient, neutron self shielding, and scattering) for unknown sample and calibrator, $R_{\sigma}$ is the ratio of effective cross sections if neutron spectrum shape differs from unknown sample to calibrator, $R_{\varepsilon}$ is the ratio of counting efficiencies (differences due to geometry and $\gamma$-ray self shielding) for unknown sample and calibrator, blank is the mass of element $x$ in the blank, $\mathrm{f}_{\mathrm{P}}$ is the correction for pulse pileup (correction method depends upon the actual hardware used) and $\mathrm{f}_{\mathrm{ltc}}$ is the correction for inadequacy of live time extension (correction method depends upon the actual hardware used)

Note that the R values are normally very close to unity, and all units are either SI-based or dimensionless ratios. Thus an uncertainty budget can be developed using only SI units and dimensionless ratios for an NAA measurement by evaluating the uncertainties for each of the terms in Eqs. (23) and (24), and for any additional corrections required (e.g., interferences, dry mass conversion factors, etc.).

Uncertainties for some of the terms in Eq. (24) have multiple components. If we sub-divide the uncertainty for each term in the above equations into individual components, add terms for potential corrections, and separate into the four stages of the measurement process, including: pre-irradiation (sample preparation); irradiation; post-irradiation (gamma-ray spectrometry), and radiochemistry, we arrive at the complete list of individual uncertainty components for NAA listed below in Table 4. Only uncertainties from the first three stages should be considered for instrumental neutron activation analysis (INAA) measurements, while all four stages should be considered for radiochemical neutron activation analysis (RNAA) measurements. More details are given in chapter 2 of reference [1] for each subsection of uncertainty component.

1. Pre-irradiation (sample and standard preparation) stage

1.1. Elemental content of standards (comparators)

1.2. Target isotope abundance ratio - unknown samples/standards

1.3. Basis mass (or other sample basis) - including drying

1.4. Sample and standard blanks

2. Irradiation stage

2.1. Neutron fluence exposure differences (ratios) for unknown samples compared to standards (comparators)

2.1. Physical effects (fluence gradients within a single irradiation)

2.2. Temporal effects (fluence variations with time)

2.3. Neutron self shielding (absorption and scattering) effects within a single sample or standard

2.4. Neutron shielding effects from neighbouring samples or standards 
2.2. Irradiation interferences

2.2.1. Fast (high energy) neutron interferences

2.2.2. Fission interferences

2.2.3. Multiple neutron capture interferences

2.3. Effective cross section differences between samples and standards

2.4. Irradiation losses and gains

2.4.1. Hot atom transfer (losses and gains by recoil, nanometer movement)

2.4.2. Transfer of material through irradiation container

2.4.3. Sample loss during transfer from irradiation container

2.4.4. Target isotope burn up differences

2.5. Irradiation timing and decay corrections during irradiation (effects of half life and timing uncertainties)

3. Gamma-ray spectrometry stage

3.1. Measurement replication or counting statistics (depending on number of replicates) for unknown samples

3.2. Measurement replication or counting statistics (depending on number of replicates) for comparator standards

3.3. Corrections for radioactive decay (effects of half life and timing uncertainties for each measurement)

3.3.1. From end of irradiation to start of measurement

3.3.2. Effects of clock time uncertainty

3.3.3. Effects of live time uncertainty

3.3.4. Count-rate effects for each measurement

3.3.4.1. Corrections for losses due to pulse pileup for conventional analyzer systems

3.3.4.2. Effects due to inadequacy of live-time extension for conventional analyzer systems

3.3.4.3. Uncertainties due to hardware corrections for Loss-Free or Zero Dead Time systems

3.4. Corrections for gamma-ray interferences

3.5. Corrections for counting efficiency differences (if necessary), or uncertainty for potential differences

3.5.1. Effects resulting from physical differences in size and shape of samples versus standards

3.5.2. Corrections for gamma-ray self absorption

3.6. Potential bias due to peak integration method

3.7. Potential bias due to perturbed angular correlations (-ray directional effects)

4. Radiochemical stage (only if radiochemical separations are employed)

4.1. Losses during chemical separation

4.2. Losses before equilibration with carrier or tracer

Table 4. Complete list of individual uncertainty components for NAA measurements using the comparator method of standardization; line numbers in this table represent subsections. 


\subsection{Detection limits of NAA}

The detection limit represents the ability of a given NAA procedure to determine the minimum amounts of an element reliably. The detection limit depends on the irradiation, the decay and the counting conditions. It also depends on the interference situation including such things as the ambient background, the Compton continuum from higher energy-rays, as well as any-ray spectrum interferences from such factors as the blank from pre-irradiation treatment and from packing materials. The detection limit is often calculated using Currie's formula:

$$
D L=2.71+4.65 B
$$

where: DL is the detection limit and B is the background under a gamma-ray peak. This relation is valid only when the gamma-ray background (counting statistical error) is the major interference.

However, practically, the INAA detection limits depend on:

1. The amount of material to be irradiated and to be counted. This is often set by availability, sample encapsulation aspects and safety limits both related to irradiation (irradiation containers) and counting (e.g. with Ge well-type detectors), and possibly because of neutron self-shielding and gamma-ray self-absorption effects. For these reasons practically the sample mass is often limited to approximately $250 \mathrm{mg}$.

2. The neutron fluxes. These are clearly set by the available irradiation facilities.

3. The duration of the irradiation time. This is set by practical aspects, such as the limitations in total irradiation dose of the plastic containers because of radiation damage. The maximum irradiation time for polyethylene capsules is usually limited to several hours, for instance 5 hours at $5 \times 10^{17} \mathrm{~m}^{-2} \mathrm{~s}^{-1}$.

4. The total induced radioactivity that can be measured is set by the state-of-the-art of counting and signal processing equipment, with additional radiation dose and shielding considerations. As an example, the maximum activity at the moment of counting may have to be limited to approximately $250 \mathrm{kBq}$.

5. The duration of the counting time. A very long counting time may set limits to the number of samples processed simultaneously in case the radioactivity decays considerably during this counting time. Moreover, it reduces sample throughput.

6. The total turn-around time. Although sometimes better detection limits may be obtained at long decay times, the demands regarding the turn-around time often imply that a compromise has to be found between the longest permissible decay time and customer satisfaction.

7. The detector size, counting geometry and background shielding. The detector's characteristics may be set in advance by availability but several options exist.

It all illustrates that the detection limit for a given element by INAA may be different for each individual type of material, and analysis conditions. In Table 5 are given, as an indica- 
tion, typical detection limits as derived from the analysis of a plant and a soil material. Peter Bode in his PhD thesis, Instrumental and organizational aspects of a neutron activation analysis laboratory, the typical detection limits as derived from the analysis of a plant and a soil material given in table 5 [26].

\begin{tabular}{lllllllll}
\hline Element & Plant & Soil & Element & Plant & Soil & Element & Plant & Soil \\
\hline $\mathrm{NA}$ & 2 & 10 & $\mathrm{Nd}$ & 0.7 & 8 & $\mathrm{Ag}$ & 0.2 & 2 \\
\hline $\mathrm{Ca}$ & 700 & 4000 & $\mathrm{Eu}$ & 0.006 & 0.05 & $\mathrm{Sn}$ & 10 & 20 \\
\hline $\mathrm{Cr}$ & 1 & 1 & $\mathrm{Yb}$ & 0.03 & 0.2 & $\mathrm{Te}$ & 0.3 & 3 \\
\hline $\mathrm{Co}$ & 0.02 & 0.3 & $\mathrm{Hf}$ & 0.01 & 0.1 & $\mathrm{Ba}$ & 10 & 40 \\
\hline $\mathrm{Zn}$ & 0.4 & 6 & $\mathrm{~W}$ & 0.3 & 1 & $\mathrm{Ce}$ & 0.2 & 1 \\
\hline $\mathrm{As}$ & 0.2 & 0.8 & $\mathrm{Os}$ & 0.1 & 0.6 & $\mathrm{Sm}$ & 0.01 & 0.03 \\
\hline $\mathrm{Br}$ & 0.3 & 0.8 & $\mathrm{Au}$ & 0.003 & 0.01 & $\mathrm{~Tb}$ & 0.008 & 0.1 \\
\hline $\mathrm{Sr}$ & 5 & 60 & $\mathrm{Th}$ & 0.01 & 0.1 & $\mathrm{Lu}$ & 0.004 & 0.02 \\
\hline $\mathrm{Mo}$ & 4 & 10 & $\mathrm{~K}$ & 200 & 1500 & $\mathrm{Ta}$ & 0.01 & 0.2 \\
\hline $\mathrm{Cd}$ & 3 & 8 & $\mathrm{Sc}$ & 0.001 & 0.02 & $\mathrm{Re}$ & 0.08 & 0.2 \\
\hline $\mathrm{Sb}$ & 0.02 & 0.2 & $\mathrm{Fe}$ & 8 & 100 & $\mathrm{Ir}$ & 0.0006 & 0.004 \\
\hline $\mathrm{Cs}$ & 0.02 & 0.3 & $\mathrm{Ni}$ & 2 & 30 & $\mathrm{Hg}$ & 0.05 & 0.4 \\
\hline $\mathrm{La}$ & 0.1 & 0.3 & $\mathrm{Ga}$ & 2 & 10 & $\mathrm{U}$ & 0.2 & 2 \\
\hline $\mathrm{Se}$ & 0.1 & 1 & $\mathrm{Rb}$ & 0.4 & 6 & $\mathrm{Zr}$ & 5 & 80 \\
\hline
\end{tabular}

Table 5. Detection limits of elements in $\mathrm{mg}^{\mathrm{kg}}{ }^{-1}$ as observed in NAA procedure of plant material and a soil material.

\section{Applications}

It is hardly possible to provide a complete survey of current NAA applications; however, some trends can be identified [27]. At specialized institutions, NAA is widely used for analysis of samples within environmental specimen banking programmes [28]. The extensive use of NAA in environmental control and monitoring can be demonstrated by the large number of papers presented at two symposia organized by the IAEA in these fields: "Applications of Isotopes and Radiation in Conservation of the Environment" in 1992 [29] and "Harmonization of Health-Related Environmental Measurements Using Nuclear and Isotopic Techniques" in 1996 [30]. Similar trends can also be identified from the topics discussed at the regular conference on "Modern Trends in Activation Analysis (MTAA)" and at the symposia on "Nuclear Analytical Methods in the Life Sciences" [31-33]. Additional sources of recent information on utilizing NAA in selected fields, such as air pollution and environmental analysis, food, forensic science, geological and inorganic materials as well as water analysis can be found in the bi-annual reviews in Analytical Chemistry, for instance 
cf. Refs [34-42]. It follows from these reviews that NAA has been applied for determining many elements, usually trace elements, in the following fields and sample types:

1. Archaeology: samples and objects such as amber, bone, ceramics, coins, glasses, jewellery, metal artefacts and sculptures, mortars, paintings, pigments, pottery, raw materials, soils and clays, stone artefacts and sculptures can be easily analyzed by NAA.

2. Biomedicine: the samples and objects that can be analysed include: animal and human tissues activable tracers, bile, blood and blood components, bone, brain cell components and other tissues, breast tissue, cancerous tissues, colon, dialysis fluids, drugs and medicines, eye, faeces, foetus, gallstones, hair, implant corrosion, kidney and kidney stones, liver, lung, medical plants and herbs, milk, mineral availability, muscle, nails, placenta, snake venom, rat tissues (normal and diseased), teeth, dental enamel and dental fillings, thyroid, urine and urinary stones.

In this work, we have used the INAA technique to analyse the traditional medicinal seeds prescribed for specific treatment purposes, were purchased from local markets [43]. The samples were irradiated at Es-Salam research reactor, at a power of $5 \mathrm{MW}$ for $6 \mathrm{~h}$. The accuracy of the method was established by analyzing reference materials. Twenty elements were measured, with good accuracy and reproducibility (Table $6^{1}$ ). The concentration of elements determined, was found to vary depending on the seeds (Fig.11). The daily intake of essential and toxic elements was determined, and compared with the recommended values. The probable cumulative intake of toxic elements is well below the tolerance limits.

\begin{tabular}{|c|c|c|c|c|}
\hline Element & Unity & Black seeds & Fenugeek & Caraway \\
\hline $\mathrm{Ba}$ & $\mathrm{mg} / \mathrm{Kg}$ & $7.7 \pm 5.5$ & $100.3 \pm 5.8$ & $112.4 \pm 6.5$ \\
\hline $\mathrm{Br}$ & $\mathrm{mg} / \mathrm{Kg}$ & $136.9 \pm 4.6$ & $119.6 \pm 3.9$ & $72.9 \pm 2.4$ \\
\hline $\mathrm{Ca}$ & $\mathrm{g} / \mathrm{Kg}$ & $3.77 \pm 4.55$ & $3.14 \pm 0.39$ & $1.50 \pm 0.21$ \\
\hline $\mathrm{Ce}$ & $\mathrm{mg} / \mathrm{Kg}$ & $1.44 \pm 0.07$ & $2.6 \pm 0.1$ & $1.98 \pm 0.11$ \\
\hline Co & $\mathrm{mg} / \mathrm{Kg}$ & $0.66 \pm 0.02$ & $0.73 \pm 0.02$ & $0.81 \pm 0.03$ \\
\hline $\mathrm{Cr}$ & $\mathrm{mg} / \mathrm{Kg}$ & $4.44 \pm 0.19$ & $29.3 \pm 1.0$ & $2.96 \pm 0.20$ \\
\hline Cs & $\mathrm{mg} / \mathrm{Kg}$ & $0.25 \pm 0.01$ & $0.51 \pm 0.02$ & $0.22 \pm 0.01$ \\
\hline Eu & $\mathrm{mg} / \mathrm{Kg}$ & $0.022 \pm 0.002$ & $0.039 \pm 0.002$ & $0.023 \pm 0.002$ \\
\hline $\mathrm{Fe}$ & $\mathrm{mg} / \mathrm{Kg}$ & $656.2 \pm 71.6$ & $823.2 \pm 89.8$ & $674.67 \pm 74.16$ \\
\hline K & $\mathrm{g} / \mathrm{Kg}$ & $3.67 \pm 1.79$ & $3.75 \pm 0.20$ & $3.7 \pm 0.2$ \\
\hline La & $\mathrm{mg} / \mathrm{Kg}$ & $0.74 \pm 0.04$ & $1.53 \pm 0.06$ & $1.50 \pm 0.06$ \\
\hline $\mathrm{Na}$ & $\mathrm{mg} / \mathrm{Kg}$ & $1028 \pm 34$ & $804.20 \pm 26.69$ & $615.50 \pm 20.41$ \\
\hline $\mathrm{Rb}$ & $\mathrm{mg} / \mathrm{Kg}$ & $24 \pm 2$ & $36.8 \pm 1.4$ & $26.3 \pm 1.9$ \\
\hline Sc & $\mathrm{mg} / \mathrm{Kg}$ & $0,258 \pm 0,037$ & $0,362 \pm 0,051$ & $0,272 \pm 0,008$ \\
\hline $\mathrm{Se}$ & $\mathrm{mg} / \mathrm{Kg}$ & $0,29 \pm 0,04$ & ND & ND \\
\hline
\end{tabular}

1 nd : not detected. 


\begin{tabular}{lllll}
\hline Element & Unity & Black seeds & Fenugeek & Caraway \\
\hline $\mathrm{Sm}$ & $\mathrm{mg} / \mathrm{Kg}$ & $0,092 \pm 0,004$ & $0,18 \pm 0,01$ & $0,142 \pm 0,005$ \\
\hline $\mathrm{Sr}$ & $\mathrm{mg} / \mathrm{Kg}$ & $203,2 \pm 7,8$ & $136,88 \pm 7,4$ & $101,7 \pm 4,7$ \\
\hline $\mathrm{Th}$ & $\mathrm{mg} / \mathrm{Kg}$ & $0,159 \pm 0,009$ & $0,32 \pm 0,02$ & $0,195 \pm 0,014$ \\
\hline $\mathrm{Zn}$ & $\mathrm{mg} / \mathrm{Kg}$ & $68,06 \pm 2,11$ & $42,8 \pm 1,4$ & $40,24 \pm 1,30$ \\
\hline
\end{tabular}

Table 6. Elemental concentrations in the medicinal seed samples (Black seeds, Fenugreek, Caraway).
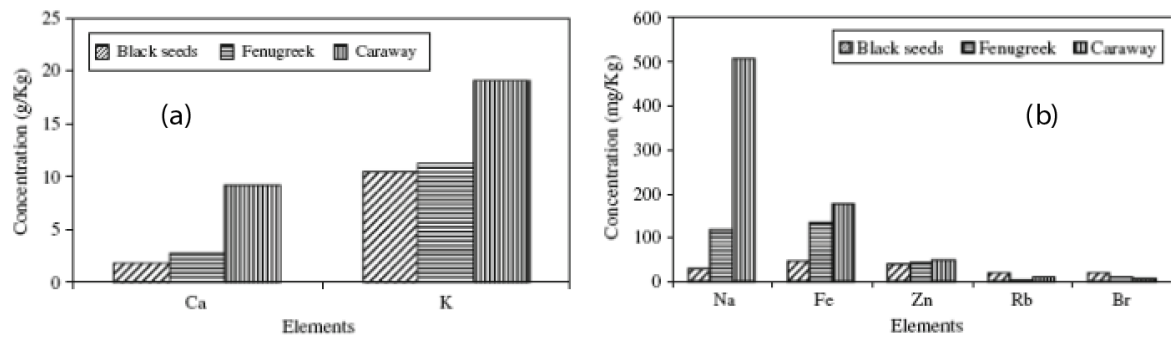

Figure 11. Concentration of the major and minor (a) and trace (b) elements in the medicinal seed samples.

3. Environmental: in this domain, related fields concerned by NAA are: aerosols, atmospheric particulates (size fractionated), dust, fossil fuels and their ashes, flue gas, animals, birds, insects, fish, aquatic and marine biota, seaweed, algae, lichens, mosses, plants, trees (leaves, needles, tree bark), household and municipal waste, rain and horizontal precipitations (fog, icing, hoarfrost), soils, sediments and their leachates, sewage sludges, tobacco and tobacco smoke, surface and ground waters, volcanic gases.

Recently, our laboratory is strongly involved in various areas of application of $\mathrm{k}_{0}$-NAA. The present work focuses on the application of the $\mathrm{k}_{0}$-NAA method in Nutritional and Health-Related Environmental field [44]. Tobacco holds a leading position among different commodities of human consumption. The adverse health effects of toxic and trace elements in tobacco smoke on smokers and non-smokers are a special concern. In the present study, the concentration of 24 trace elements in cigarette tobacco of five different brands of Algerian and American cigarettes have been determined by $\mathrm{k}_{0}$-based INAA method. The results were compared with those obtained for samples from Iranian, Turkish, Brazilian and Mexican cigarettes tobacco. To evaluate the accurate of the results the SRM IAEA-140/TM was executed.

A multi-element analysis procedure based on the $\mathrm{k}_{0}$-NAA method was developed at EsSalam research reactor allowing to simultaneously determine concentrations for 24 elements (As, Ba, Br, Ca, Ce, Co, Cr, Cs, Eu, Fe, Hf, K, La, Na, Rb, Sb, Sc, Se, Sm, Sr, Ta, 
$\mathrm{Tb}, \mathrm{Th}, \mathrm{Zn})$. The determination of toxic and trace elements in cigarette tobacco is important both from the point of view of health studies connected with smoking and more general aspects of the uptake of trace elements by plants (table 7). Because of its great sensitivity, $\mathrm{k}_{0}$-NAA method is very suitable for determination of heavy metals such as $\mathrm{As}, \mathrm{Sb}$, Se and $\mathrm{Zn}$. The accuracy of the results was checked by the analysis of standard reference material and good agreement was obtained with certified or literature values. The results of Algerian tobacco (table 8) were compared with analyses of Turkey [45], Iran [46], Mexican [47] and Brazilian tobacco [48].

\begin{tabular}{|c|c|c|c|c|c|}
\hline \multirow{2}{*}{ Element } & \multicolumn{5}{|c|}{ Designated sample code } \\
\hline & T1 & $\mathrm{T} 2$ & T3 & T4 & T5 \\
\hline As & $4.05 \pm 0.16$ & $6.4 \pm 0.24$ & $2.16 \pm 0.09$ & $2.42 \pm 0,09$ & $4.27 \pm 0.28$ \\
\hline $\mathrm{Ba}$ & $101.3 \pm 5.5$ & $100.3 \pm 5.8$ & $112.4 \pm 6.5$ & $83.1 \pm 4.4$ & $120.0 \pm 7.7$ \\
\hline $\mathrm{Br}$ & $136.9 \pm 4.6$ & $119.6 \pm 3.9$ & $72.9 \pm 2.4$ & $54.1 \pm 1.7$ & $68.7 \pm 2.3$ \\
\hline Ca \% & $3.77 \pm 4.55$ & $3.14 \pm 0.39$ & $1.50 \pm 0.21$ & $2.11 \pm 0.26$ & $2.39 \pm 0.31$ \\
\hline $\mathrm{Ce}$ & $1.44 \pm 0.07$ & $2.6 \pm 0.1$ & $1.98 \pm 0.11$ & $1.01 \pm 0.05$ & $1.81 \pm 0.11$ \\
\hline Co & $0.66 \pm 0.02$ & $0.73 \pm 0.02$ & $0.81 \pm 0.03$ & $0.51 \pm 0.02$ & $0.78 \pm 0.03$ \\
\hline $\mathrm{Cr}$ & $4.44 \pm 0.19$ & $29.3 \pm 1.0$ & $2.96 \pm 0.20$ & $2.37 \pm 0.11$ & $2.80 \pm 0.22$ \\
\hline Cs & $0.25 \pm 0.01$ & $0.51 \pm 0.02$ & $0.22 \pm 0.01$ & $0.191 \pm 0.008$ & $0.42 \pm 0.02$ \\
\hline $\mathrm{Eu}$ & $0.022 \pm 0.002$ & $0.039 \pm 0.002$ & $0.023 \pm 0.002$ & $0.021 \pm 0.001$ & $0.032 \pm 0.002$ \\
\hline $\mathrm{Fe}$ & $656 \pm 72$ & $823 \pm 90$ & $675 \pm 74$ & $384 \pm 13$ & $664 \pm 24$ \\
\hline $\mathrm{Hf}$ & $0.127 \pm 0.007$ & $0.224 \pm 0.015$ & $0.24 \pm 0.02$ & $0.144 \pm 0.014$ & $0.143 \pm 0.010$ \\
\hline$K \%$ & $3.67 \pm 1.79$ & $3.75 \pm 0.20$ & $3.7 \pm 0.2$ & $2.92 \pm 0.14$ & $3.38 \pm 0.18$ \\
\hline La & $0.74 \pm 0.04$ & $1.53 \pm 0.06$ & $1.50 \pm 0.06$ & $1.082 \pm 0.043$ & $1.68 \pm 0.06$ \\
\hline $\mathrm{Na}$ & $1028 \pm 34$ & $804 \pm 27$ & $616 \pm 20$ & $653 \pm 22$ & $575 \pm 19$ \\
\hline $\mathrm{Rb}$ & $24 \pm 2$ & $36.8 \pm 1.4$ & $26.3 \pm 1.9$ & $14.33 \pm 0.59$ & $25.4 \pm 1.6$ \\
\hline $\mathrm{Sb}$ & $0.089 \pm 0.014$ & $0.180 \pm 0.020$ & $0.036 \pm 0.007$ & $0.127 \pm 0.015$ & $0.346 \pm 0.037$ \\
\hline Sc & $0.258 \pm 0.037$ & $0.362 \pm 0.051$ & $0.272 \pm 0.008$ & $0.165 \pm 0.023$ & $0.264 \pm 0.037$ \\
\hline $\mathrm{Se}$ & $0.29 \pm 0.04$ & ND & ND & ND & ND \\
\hline Sm & $0.092 \pm 0.004$ & $0.18 \pm 0.01$ & $0.142 \pm 0.005$ & $0.095 \pm 0.004$ & $0.152 \pm 0.005$ \\
\hline
\end{tabular}




\begin{tabular}{|c|c|c|c|c|c|}
\hline \multirow{2}{*}{ Element } & \multicolumn{5}{|c|}{ Designated sample code } \\
\hline & T1 & $\mathrm{T} 2$ & T3 & T4 & T5 \\
\hline $\mathrm{Sr}$ & $203.2 \pm 7.8$ & $136.9 \pm 7.4$ & $101.7 \pm 4.7$ & $82.37 \pm 3.62$ & $106.80 \pm 5.39$ \\
\hline $\mathrm{Ta}$ & $0.021 \pm 0.003$ & $0.043 \pm 0.006$ & $0.023 \pm 0.004$ & $0.029 \pm 0.004$ & $0.023 \pm 0.004$ \\
\hline $\mathrm{Tb}$ & $0.018 \pm 0.004$ & $0.021 \pm 0.003$ & $0.014 \pm 0.004$ & $0.008 \pm 0.002$ & $0.018 \pm 0.004$ \\
\hline Th & $0.159 \pm 0.009$ & $0.32 \pm 0.02$ & $0.195 \pm 0.014$ & $0.153 \pm 0.012$ & $0.19 \pm 0.02$ \\
\hline $\mathrm{Zn}$ & $68.06 \pm 2.11$ & $42.8 \pm 1.4$ & $40.24 \pm 1.30$ & $27.53 \pm 0.89$ & $42.99 \pm 1.38$ \\
\hline
\end{tabular}

Table 7. Concentration values ( $\mathrm{mg} \mathrm{kg}-1$ ) of five brands of tobacco by $\mathrm{k}_{0}-\mathrm{NAA}$ method.

\begin{tabular}{|c|c|c|c|c|c|}
\hline Element & Algeria & Turkey & Iran & Mexican & Brazilian \\
\hline As & $4.05-6.4$ & 1.0 & - & $<0.55-3.24$ & - \\
\hline $\mathrm{Ba}$ & $100.3-101.3$ & 64.6 & $1.15 \pm 0.01$ & $64-251$ & $45.8-99.7$ \\
\hline $\mathrm{Br}$ & $119.6-136.9$ & 59.2 & $137 \pm 2$ & $49-136$ & - \\
\hline $\mathrm{Ca} \%$ & $3.14-3.77$ & - & - & - & - \\
\hline $\mathrm{Ce}$ & $1.44-2.6$ & - & $1.19 \pm 0.02$ & $<0.3-1.7$ & $1.2-8.3$ \\
\hline Co & $0.66-0.73$ & 0.77 & $0.21 \pm 0.01$ & $0.29-0.55$ & $0.70-1.2$ \\
\hline $\mathrm{Cr}$ & $4.44-29.3$ & 7.1 & $3.14 \pm 0.14$ & $<0.8-2.4$ & - \\
\hline Cs & $0.25-0.51$ & 0.20 & $0.17 \pm 0.02$ & $0.091-0.4$ & - \\
\hline $\mathrm{Eu}$ & $0.022-0.039$ & 0.034 & $0.045 \pm 0.010$ & $<0.03$ & $0.036-0.037$ \\
\hline $\mathrm{Fe}$ & $656.2-823.2$ & 1000 & $649 \pm 6$ & $420-680$ & $710-4100$ \\
\hline $\mathrm{Hf}$ & $0.127-0.224$ & 0.15 & $0.09 \pm 0.01$ & $<0.03-0.13$ & $0.15-0.87$ \\
\hline$K \%$ & $3.67-3.75$ & 2.6 & $0.220 \pm 0.005$ & $1.83-4.03$ & - \\
\hline La & $0.74-1.53$ & 1.0 & $0.62 \pm 0.02$ & $<0.2-0.66$ & $1.9-4.8$ \\
\hline $\mathrm{Na}$ & $804.2-1028$ & 394 & $347 \pm 18$ & $309-566$ & - \\
\hline $\mathrm{Rb}$ & $24.0-36.8$ & 17.7 & $22.6 \pm 3.6$ & $19-50$ & $30.3-45.0$ \\
\hline $\mathrm{Sb}$ & $0.089-0.180$ & 0.10 & $0.68 \pm 0.03$ & $<0.7$ & $0.079-0.47$ \\
\hline Sc & $0.258-0.362$ & 0.35 & $0.43 \pm 0.03$ & $0.13-0.22$ & $0.23-1.50$ \\
\hline
\end{tabular}




\begin{tabular}{llllll}
\hline Element & Algeria & Turkey & Iran & Mexican & Brazilian \\
\hline Se & 0.29 & 0.18 & - & $<0.7$ & - \\
\hline $\mathrm{Sm}$ & $0.092-0.180$ & - & $0.88 \pm 0.01$ & $0.07-0.14$ & $0.24-0.60$ \\
\hline $\mathrm{Sr}$ & $136.88-203.20$ & - & - & $227-472$ & - \\
\hline $\mathrm{Ta}$ & $0.021-0.043$ & - & - & - & - \\
\hline $\mathrm{Tb}$ & $0.018-0.021$ & - & $0.034 \pm 0.002$ & - & - \\
\hline $\mathrm{Th}$ & $0.159-0.320$ & 0.32 & $0.177 \pm 0.010$ & $<0.1-0.17$ & $0.34-4.00$ \\
\hline $\mathrm{Zn}$ & $42.80-68.06$ & 35 & $12.6 \pm 0.4$ & $14-56$ & - \\
\hline
\end{tabular}

Table 8. Comparison between our results (Algerian cigarettes tobacco) and those reported in the literature.

4. Forensics: bomb debris, bullet lead, explosives detection, glass fragments, paint, hair, gunshot residue swabs, shotgun pellets.

5. Geology and geochemistry: asbestos, bore hole samples, bulk coals and coal products, coal and oil shale components, crude oils, kerosene, petroleum, cosmo-chemical samples, cosmic dust, lunar samples, coral, diamonds, exploration and geochemistry, meteorites, ocean nodules, rocks, sediments, soils, glacial till, ores and separated minerals.

6. Industrial products: alloys, catalysts, ceramics and refractory materials, coatings, electronic materials, fertilizers, fissile material detection and other safeguard materials, graphite, high purity and high-tech materials, integrated circuit packing materials, online, flow analysis, oil products and solvents, pharmaceutical products, plastics, process control applications, semiconductors, pure silicon and silicon processing, silicon dioxide, NAA irradiation vials, textile dyes, thin metal layers on various substrates.

7. Nutrition: composite diets, foods, food colours, grains, honey, seeds, spices, vegetables, milk and milk formulae, yeast. In this chapter, we focus on the application of the $\mathrm{k}_{0}$ method of instrumental neutron activation analysis in Nutritional and Health-Related Environmental field [49]. Three kinds of milk were purchased in the powder form from local supermarket. The samples of milk powder were analyzed using $\mathrm{k}_{0}$-NAA method. Concentrations of six elements $\mathrm{Br}, \mathrm{Ca}, \mathrm{K}, \mathrm{Na}, \mathrm{Rb}$ and $\mathrm{Zn}$ have been determined by long irradiation time with a thermal and epithermal flux of $4.7 .10^{12} \mathrm{n} \cdot \mathrm{cm}^{-2} \cdot \mathrm{s}^{-1}$ and $2.29 .10^{11}$ n. $\mathrm{cm}^{-2} \cdot \mathrm{s}^{-1}$, respectively (see table 9). The reactor neutron spectrum and detection efficiency calibration parameters such as $\alpha, \mathrm{f}$ and $\varepsilon \mathrm{p}$ have been used for the calculation of elemental concentrations. The analytical results for three kinds of milk using $\mathrm{k}_{0}$-NAA are compared with the certified values of SRMs. In this work, we have determined six elements in three kinds of milk and two reference materials, IAEA-153 and IAEA-155. The elements $\mathrm{Br}, \mathrm{Ca}, \mathrm{K}, \mathrm{Na}, \mathrm{Rb}$ and $\mathrm{Zn}$ were determined in each kind of the three samples of milk. 


\begin{tabular}{llll}
\hline \multirow{2}{*}{ Element } & \multicolumn{3}{l}{ Element Designated sample code } \\
\cline { 2 - 4 } & $\mathbf{M} 1$ & $\mathbf{M} 2$ & $\mathbf{M 3}$ \\
\hline $\mathrm{Br}$ & $12.74 \pm 0.81$ & $38.9 \pm 1.26$ & $72.73 \pm 0.56$ \\
$\mathrm{Ca}$ & $9040 \pm 150(9300)$ & $9560 \pm 820(9600)$ & $9210 \pm 130$ \\
\hline $\mathrm{K}$ & $12970 \pm 780(12000)$ & $12700 \pm 700(12600)$ & $12700 \pm 500$ \\
\hline $\mathrm{Na}$ & $280 \pm 100(3500)$ & $33900 \pm 100(4400)$ & $41400 \pm 130$ \\
\hline $\mathrm{Rb}$ & $12.03 \pm 0.08$ & $14.7 \pm 0.7$ & $8.2 \pm 0.8$ \\
\hline $\mathrm{Zn}$ & $48.03 \pm 0.08$ & $42.7 \pm 0.2$ & $42.4 \pm 0.2$ \\
\hline
\end{tabular}

Table 9. Concentration values of Milk: M1, M2 and M3; units are in mg/kg, NB: (value) is the concentration value of indicated by producer.

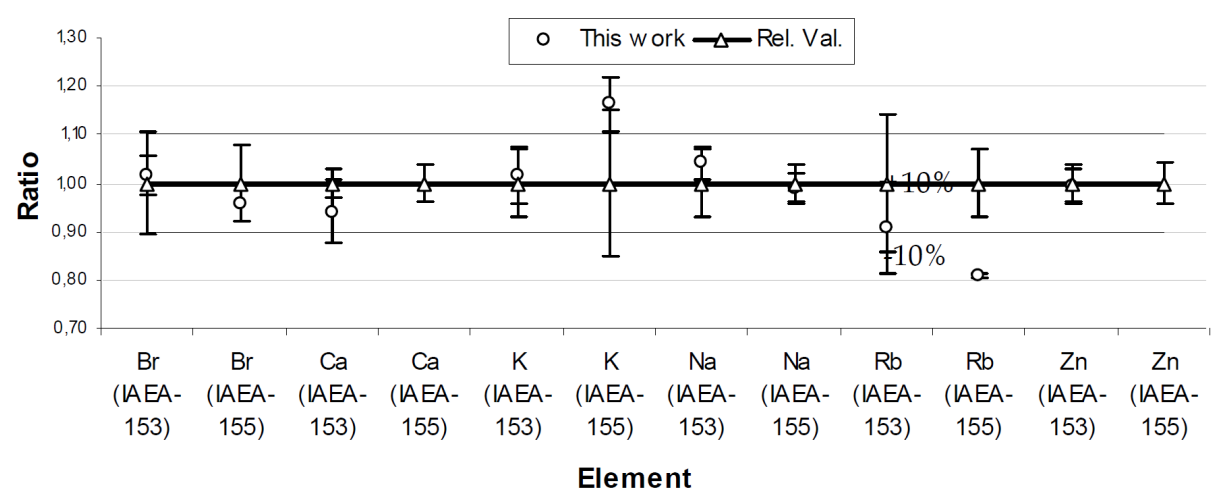

Figure 12. Comparison of $k_{0}$-NAA data to certified values for IAEA-153 and IAEA-155.

The accuracy of the measurements was evaluated by analyzing two SRMs Whey powder AIEA-155 and Milk powder AIEA-153. The analysis results illustrated in figure 12 showed that the deviations between experimental and certified values were mostly less than $10 \%$.

As an example, an investigation in the nutrition field was carried out by the radiochemical neutron activation analysis to the proportioning of iodine in food salt [50].

8. Quality assurance: this include analysis of reference materials, certification of element contents and homogeneity testing of mainly biological and environmental reference materials of chemical composition and methods inter-comparisons. Additional information about these applications can be found in the Proceedings of the Int. Symposia on Biological and Environmental Reference Materials (BERM). In 2012, Hamidatou L et all 
reported "k0-NAA quality assessment in an Algerian laboratory by analysis of SMELS and four IAEA reference materials using Es-Salam Research reactor" the internal quality control of the k0-NAA technique [51]. The concept of QC/QA, internal and external validation is considered as an advanced stage in the life cycle of an analytical method.

Our contribution in this domain is considered as periodic activities. Since the Nineties our laboratory participated through AFRA/AIEA projects in different inter-laboratory proficiency tests. Recently, our laboratory was participated in four inter-comparison tests organized by IAEA within the framework of the AFRA project to assess the analytical performance of 18 analytical laboratories participating in the RAF /4/022 project, Enhancement of Research Reactor Utilization and Safety by taking part in analytical proficiency testing IAEA in conjunction with WEPAL, the Wageningen Evaluating Programs for Analytical Laboratories. The Proficiency Testing tests related to the determination of major, minor and trace elements in materials of the International Soil and Plant Analytical Exchange material (Wepal codes ISE, IPE).

9. Neutron flux characterization: theoretical and experimental study, calibration of irradiation channels, simulations using Monte Carlo Code. In general, the implementation of new techniques based on the neutron beams or flux around the research reactors needs the knowledge of the essential parameters of neutron flux in different sites to obtain a better precision during the development.

In this context, we give a great interest in the neutron study for our irradiation channels by making periodic calibrations using experimental and simulation approaches [11, 15, 52].

\section{Conclusions}

NAA plays a complementary role in materials analysis in an industrial analytical laboratory. There are applications where it is highly desirable, and may play the dominant role as the method of choice e.g. bulk analysis of Si. The advantages of NAA are still the minimum sample preparation and ultra high sensitivity while turnaround time and lack of spatial resolution is a significant limitation.

The many diverse applications in varied fields show that NAA is extremely useful, even though it is a relatively simple analytical method. Irradiation of samples may be done at nuclear reactors that offer such services. Such centres are easily accessible nowadays. Even if these centres are inaccessible, other neutron sources that emit thermal neutrons may be used. Hence any laboratory that has a gamma counter can perform NAA experiments. Development of research programs based on NAA is accessible to any laboratory that is willing to invest a minimal amount of funds. In this chapter, we have presented the neutron activation analysis in different angles such as: basis principles, derivation of several equations, techniques, procedures, etc. In addition, we have associated in each part of general work, some examples of our technical developments and applications of NAA method in several fields. All analytical works were executed in our centre using irradiation facilities of 
Es-Salam research reactor and all necessary equipments installed in the NAA department to cover all steps of analytical process.

\section{Acknowledgments}

Thanks are due to Dr Derdour Mohamed the responsible of COMENA and Mr Kerris Abdelmoumen General Director of CRNB for financial support. Grateful acknowledgment is made to Mr Salhi Mhamed the director of techniques and nuclear applications division for his highly valuable assistance. Special thanks are due to all colleagues involved for their help during fifteen years.

\section{Author details}

Lylia Hamidatou, Hocine Slamene, Tarik Akhal and Boussaad Zouranen

Department of Neutron Activation Analysis, Nuclear Research Centre of Birine, Algeria

\section{References}

[1] Greenberg, R.R., et al., Spectrochimica Acta Part B, 66 issues 3-4; 2011, p193-241.

[2] Bé, M. M., Chisté. V., BNM-LNHB/CEA- Tables des radionucléides, 01/12/01-6/4/2004; 2004.

[3] De Corte, F.,The $\mathrm{k}_{0}$ Standardization Method: A Move to the Optimization of NAA, Gent University; 1987.

[4] De Corte, F., et al.,J. Radioanal. Nucl. Chem., volume 197; 1994, p93.

[5] Acharya, R., Chatt, A.,. J. Radioanal. Nucl. Chem., volume 257; 2003, p525.

[6] Simonits, A., De Corte, F., Hoste, J., J. Radioanal. Chem., volume 24; 1975, p. 31.

[7] Lin, X., Li, X., J. Radioanal. Nucl. Chem., volume 223; 1997, p. 47.

[8] Moens, L., De Corte, F., Simonits, A., De Wilspelaere, A., Hoste, J., J. Radioanal. Chem., volume $52 ; 1979$, p. 379.

[9] De Corte, F., Simonits, A., De Wilspelaere, A., Hoste, J., J. Radioanal. Nucl. Chem., volume 113; 1987, p145.

[10] Jovanovic, S., De Corte, F., Moens, L., Simonits, A., Hoste, J., J. Radioanal. Nucl. Chem., volume 82; 1984, p.379. 
[11] Alghem, L., Ramdhane ,M., S. Khaled, T. Akhal., The development and application of $\mathrm{k}_{0}$-standardization method of neutron activation analysis at Es-Salam research reactor, Nucl. Instr. and methods., 556; 2006, p386-390.

[12] Mustra, C. O., Freitas, M. C., Alimeida, S. M. (). J. Radioanal. Nucl. Chem. volume 257; 2003, p539.

[13] HyperLab 2005 System: Installation and Quick Start Guides. HyperLabs Software, Budapest, Hungary; 2005.

[14] De Corte, F, Simonits, A, De Wispelaere, A., Hoste, J., Accuracy and applicability of the $\mathrm{k}_{0}$-standardozation method. J Radioanal Nucl Chem volume 113; 1987,. p145-154.

[15] Alghem Hamidatou, L., Ramdhane, M., Characterization of neutron spectrum at EsSalam Research Reactor using Høgdahl convention and Westcott formalism for the k0-based neutron activation analysis, Journal of Radioanalytical and Nuclear volume 278 issue (3); 2008, p627-630.

[16] Dung, H.M., Hien, P.D., J. Radioanal. Chem. volume 257; 2003, p643.

[17] De Corte, F., Simonits, A., Bellemanns, F, Freitas, MC., Jovanovic, S, Smodis, B., Erdtmann G., Petri, H., De Wispelaere, A., Recent advances in the $\mathrm{k}_{0}$-standardization of neutron activation analysis: Extensions, applications, prospects. J Radioanal Nucl Chem volume 169; 1993, p125-158.

[18] Kennedy, G., ST-Pierre, J., Wang, K., Zhang, Y., Preston, J., Grant, C., Vutchkov, M., Activation constants for Slowpoke and MNS Reactors calculated from the neutron spectrum and $\mathrm{k}_{0}$ and $\mathrm{Q}_{0}$ values. J Radioanal Nucl Chem volume 245; 2000, p167-172.

[19] Acharya, RN., Nair, AGC., Reddy, AVR., Manohar, SB. () Validation of a neutron activation analysis method using $\mathrm{k}_{0}$-standardization. Appl. Radiation Isotopes, volume 57; 2002, p391-398.

[20] Kragten, J., Calculating standard deviations and confidence intervals with a universally applicable spreadsheet technique, Analyst volume 119; 1994, p2161-2166.

[21] Rees, C.E., Error propagation calculations, Geochim. Cosmochim. Acta volume 48; 1984

[22] Ellison, S.L.R., Rosslein, M., Williams, A., Quantifying Uncertainty in Analytical Measurements (2nd ed.; QUAM:2000.P1), Eurachem/CITAC; 2000.

[23] Robouch, P., Arana, G., Eguskiza, M., Pommé, S., Etxebarria, N., Uncertainty budget for k0-NAA, J. Radioanal. Nucl. Chem. volume 245; 2000, p195-197.

[24] Joint Committee for Guides in Metrology, Evaluation of measurement data - Supplement 1 to the "Guide to the expression of uncertainty in measurement" - Propagation of distributions using a Monte Carlo method JCGM101:2008 (ISO/IEC Guide 98-3-1); 2008. 
[25] Joint Committee for Guides in Metrology, Evaluation of measurement data - Guide to the expression of uncertainty in measurement (2008) JCGM 101:2008 (ISO/IEC Guide 98-3); 2008.

[26] Bode, P., Instrumental and organizational aspects of a neutron activation analysis laboratory Ph.D. dissertation, Delft University of Technology, Delft; 1996.

[27] IAEA TEC-DOC, 1215; 2001.

[28] Rossbach, M., Emons, H., Groemping, A., Ostapczuk, P., Schladit, J.D., Quality control strategies at the environmental specimen bank of the Federal Republic of Germany, Harmonization of Health-Related Environmental Measurements Using Nuclear and Isotopic Techniques, (Proc. Symp. Hyderabad, India, 1996), IAEA, Vienna; 1997, p89-100.

[29] International Atomic Energy Agency, Applications of Isotopes and Radiation in Conservation of the Environment (Proc. Symp. Karlsruhe, Germany, 1992), IAEA, Vienna; 1992.

[30] International Atomic Energy Agency, Harmonization of Health-Related Environmental Measurements Using Nuclear and Isotopic Techniques, (Proc. Symp. Hyderabad, India, 1996), IAEA, Vienna; 1997.

[31] Zeisler, R., Guinn, V.P., Nuclear Analytical Methods in the Life Sciences, Biol. Trace El. Res., 26/27, Humana Press, Clifton, New Jersey; 1990.

[32] Kucera, J., Obrusnik, I., Sabbioni, E., Nuclear Analytical Methods in the Life Sciences, Biol. Trace El. Res., 43/45, Humana Press, Totowa, New Jersey; 1994.

[33] Chai, Z., (Ed.), Nuclear Analytical Methods in the Life Sciences, (1999). Biol. Trace El. Res.71, Humana Press, Totowa, New Jersey.

[34] Ehmann, W.D., Yates, S.W.Nuclear and radiochemical analysis, Anal. Chem. 58 49R-65R, 1986.

[35] Ehmann, W.D., Yates, S.W., Nuclear and radiochemical analysis, Anal. Chem. 60 42R-62R; 1988.

[36] Ehmann, W.D., Robertson, J.D., Yates, S.W., Nuclear and radiochemical analysis, Anal. Chem. 62 5OR-70R; 1990.

[37] Ehmann, W.D., Robertson, J.D., Yates, S.W., Nuclear and radiochemical analysis, Anal. Chem. 64 1R-22R; 1992.

[38] Ehmann, W.D., Robertson, J.D., Yates, S.W., Nuclear and radiochemical analysis, Anal. Chem. 66 229R-251R; 1994.

[39] Application reviews, Analytical Chemistry 63, No. 12 1R-324R; 1991.

[40] Application reviews, Analytical Chemistry 65, No. 12 1R-484R; 1993.

[41] Application reviews, Analytical Chemistry 67, No. 12 1R-583R; 1995. 
[42] Application reviews, Analytical Chemistry 69, No. 12 1R-328R; 1997.

[43] Khaled, S., Mouzai, M., Ararem, A., Hamidatou, L., Zouranen, B., Elemental analysis of traditional medicinal seeds by instrumental neutron activation analysis. J Radioanal Nucl Chem volume 281; 2009, p87-90.

[44] Hamidatou, L. A,. Khaled, S., Akhal, T., Ramdhane, M., Determination of trace elements in cigarette tobacco with the $\mathrm{k}_{0}$-based NAA method using Es-Salam research reactor. J Radioanal Nucl Chem, volume 281; 2009, p535-540

[45] Gülovali, M.C., Gunduz, G., J. Radioanal. Chem., volume 78; 1983, p189-198.

[46] Abedinzadeh, Z., Razechi, M., Parsa, B., J. Radioanal. Chem. volume 35, 1977,p373-379.

[47] Vega-Carrillo, H.R., Iskander, F.Y., Manzanres-Acuna, E., J. Radioanal. Nucl. Chem. Lett., volume 200; 1995, p137-145.

[48] Munita, C.S., Mazzillil, B.P., J. Radioanal. Nucl. Chem. Lett, volume 108; 1986, p217-227.

[49] Hamidatou, L. A., Khaled, S., Mouzai, M., Zouranen, B., Ararem, A., Alghem, A., Ramdhane, M., Instrumental neutron activation analysis of milk samples using the $\mathrm{k}_{0}$-standardization method at Es-Salam research reactor. Phys. Chem. News volume 45; 2009, p44-47.

[50] Akhal, T., Mouzai, M., Sana, Y., Ladjel, M., Application of RNAA to the proportioning of iodine in food salt. Phys. Chem. News volume 45; 2009, p34-38.

[51] Hamidatou, L. A., S. Dakar, S. Boukari, k0-NAA quality assessment in an Algerian laboratory by analysis of SMELS and four IAEA reference materials using Es-Salam Research reactor, Journal of Nuclear Instruments and methods in physics research section A., 682 (2012) p 75-78.

[52] Hamidatou, L., Benkharfia, H Experimental and MCNP calculations of neutron flux parameters in irradiation channel at Es-Salam reactor, J. Radioanal. Nucl. Chem., V287, N³ (2011) p971-975. 